\title{
DISUASIÓN DE ENTRADA, SUBASTAS REPETIDAS Y DIVISIBILIDAD DEL OBJETO EN VENTA*
}

ENTRY DETERRENCE, REPEATED AUCTIONS AND DIVISIBILITY OF THE OBJECT IN SALE

\author{
JULIO PEÑA-TORRES** \\ Gabriel Fernández AguirRE****
}

\begin{abstract}
Resumen
Este trabajo analiza estrategias de disuasión de entrada en una secuencia de subastas tipo inglesa, con venta de múltiples derechos de producción. Esto, motivado por intentos de entrada infructuosos observados en algunas de las subastas anuales de derechos de pesca ocurridas desde inicios de los años 1990 en la pesquería industrial del Bacalao de Profundidad en Chile. Se analizan condiciones paramétricas bajo las cuales las firmas incumbentes podrían haber logrado disuadir entrada en forma no cooperativa, o bien habrían requerido coludirse para tal fin. Se desarrolla un modelo con dos etapas de competencia. En la primera etapa se subastan secuencialmente múltiples derechos de pesca; en la segunda etapa, esos derechos se usan para competir en un mercado Cournot de bien homogéneo. El análisis se focaliza en la relación entre número de incumbentes, fuentes de ventaja competitiva para éstos y el número y tamaño productivo de múltiples derechos de pesca en venta. El énfasis está en analizar cómo la divisibilidad del objeto en venta afecta las posibilidades de los incumbentes para disuadir la entrada de nuevos rivales.
\end{abstract}

Palabras clave: Colusión, Barreras a la entrada, Subastas repetidas, Free-riding.

* Se agradece a CONICYT el apoyo financiero aportado a través del Programa Regional STIC-AMSUD 2007-2009/Proyecto MIFIMA. También los valiosos comentarios y sugerencias de Emanuel Vespa (Econ.-NYU), Manuel Willington y Eduardo Saavedra (Econ.-UAH), Hugo Salgado (Econ.-U. de Concepción), de los participantes en los seminarios del grupo de Economía-UAH y, además, las ideas aportadas por dos árbitros anónimos. Asimismo, se agradece a personal de la Subsecretaría de Pesca por brindar información relevante al caso analizado, especialmente a Ricardo Radebach y Marcelo García. El disclaimer usual aplica.

** Profesor Adjunto, Facultad de Economía y Negocios, Universidad Alberto Hurtado/ ILADES, Erasmo Escala 1835, Santiago, Chile, E-mail: jpena@uahurtado.cl (autor de contacto).

*** Economista miembro de la División Económica, Fiscalía Nacional Económica de Chile (gfernandez@fne.gob.cl). Las opiniones expresadas en este artículo son de exclusiva responsabilidad de sus autores y no necesariamente representan a las instituciones donde trabajan. 


\begin{abstract}
This paper analyzes entry deterrence strategies at sequential multi-unit Englishtype repeated auctions, motivated by entry deterrence observed at a series of yearly auctions of fishing rights occurring since the early 1990s in the Chilean Sea Bass industrial fishery. It analyzes parametric configurations under which incumbent firms may have followed non-cooperative entry deterrence strategies or else may have colluded for that purpose. A two-stage competition model is developed. In the first stage there occurs sequential auctioning of multiple fishing rights; in the second stage, production rights are used to compete in a homogeneous-good Cournot market. The analysis focuses on the relationship between the number of incumbents, sources of competitive advantage for them (relative to potential entrants) and the number and productive size of the multiple production rights in sale. The core of the analysis lies in answering how does the divisibility of the object(s) in sale affect the possibilities of incumbent firms for deterring the entry of new rivals.
\end{abstract}

Key words: Collusion; Entry Deterrence; Repeated Auctions; Free Riding.

JEL Classification: D2, D4, $Q 2$.

\title{
1. INTRODUCCIÓN
}

Este trabajo analiza los resultados de adjudicación en dos del total de subastas anuales que han ocurrido desde principios de los 1990 para adjudicar derechos de pesca en Chile para la captura industrial de bacalao de profundidad (Dissostichus eleginoides), también conocido por su nombre comercial de Chilean Sea Bass. Las dos subastas que motivan este análisis son las únicas en las que ocurrieron intentos (infructuosos) de entrada por parte de nuevos rivales. En el debate público se ha argumentado que estos fracasos de entrada fueron resultado de colusión en las subastas entre las firmas incumbentes.

A la fecha, no existe ningún análisis publicado sobre la experiencia en Chile con subastas para asignar cuotas individuales de pesca. Y esto, en un contexto mundial en el cual el uso de subastas para asignar derechos de pesca ha sido, hasta ahora, excepcional (un par de raras excepciones son los casos de la pesquería de la almeja (geoduck) en el estado de Washington (US) y pesquerías en Estonia y en el Este de Rusia véase Huppert, 2005; Anferova et al., 2005; Vetemaa et al., 2002). A pesar de ello, en años recientes se ha desarrollado creciente debate en diversos países sobre la posibilidad de implementar cuotas individuales de pesca. Perú es un reciente caso de implementación de un sistema de regulación pesquera de este tipo (desde fines del 2008). Otro caso es Estados Unidos, en donde actualmente se desarrolla una activa discusión pública sobre la posibilidad de extender el uso de cuotas individuales de pesca como instrumento base de regulación pesquera.

La motivación inmediata del presente trabajo es contribuir a perfeccionar el debate que en Chile ha ocurrido sobre la posibilidad de que las firmas incumbentes en la pesquería analizada se hayan coludido, para así reducir los precios 
de adjudicación de los derechos de pesca subastados y también evitar la entrada de nuevos rivales al negocio de exportación del bacalao de profundidad.

Las lecciones deducibles a partir de este análisis son también válidas para otros sectores productivos en donde se necesite asignar múltiples derechos de producción, de forma repetida en el tiempo y mediante licitación pública. En la literatura económica existen diversos ejemplos. Incluyen desde la asignación de licencias para prestar servicios de transporte aéreo; asignar derechos para uso del espectro electromagnético (Klemperer, 2008); sobre la asignación de contratos de concesión para inversiones en infraestructura de acceso público, como carreteras y puertos (Porter y Zona, 1993); respecto a la obtención de patentes en procesos de inversión secuencial en innovación tecnológica (Gilbert y Newbery, 1982; Krishna, 1993); sobre la asignación de derechos para explorar y explotar terrenos estatales con aptitud forestal (Baldwin et al., 1997; Athey y Levin, 2001), o para asignar áreas marinas con reservas subterráneas de petróleo y gas natural (Porter, 1995; Hendricks y Porter, 1988).

En varios de los trabajos citados se discuten resultados colusorios en subastas repetidas y con venta de múltiples unidades de producto. De hecho, en años recientes se ha acumulado creciente literatura, teórica y empírica, sobre los incentivos de competencia y la posibilidad de colusión en contextos de este tipo (e.g., Klemperer, 2004, 2008; Hendricks y Porter, 2007). El énfasis predominante ha sido analizar cómo distintos supuestos informacionales condicionan a las estrategias usadas por los competidores (e.g., Hendrick y Porter, 1988; Baldwin et al., 1997; Athey y Levin, 2001).

En contraste, el foco en este trabajo es estudiar cómo la divisibilidad de los derechos de producción en venta ${ }^{1}$ influye sobre (i) los incentivos a disuadir entrada y (ii) las condiciones paramétricas en las cuales tal disuasión podría ocurrir de forma no cooperativa, o bien requeriría colusión entre los incumbentes. Al respecto, se considera el número y tamaño de los derechos de pesca en venta, el número de incumbentes, junto con posibles fuentes de ventajas de competencia para los incumbentes, como la existencia de costos hundidos. La divisibilidad de los derechos en venta se modela parametrizando el número de derechos por licitar, manteniendo constante el volumen total de producción a ser licitado (dada una cuota máxima de producción, definida exógenamente). Este último supuesto de modelamiento es razonable y con aplicación intuitiva directa al caso específico que motiva este trabajo. Esta variante de modelamiento, junto al considerar en forma explícita la posibilidad de disuadir entrada en forma no cooperativa o bien vía colusión, representan un aporte a la literatura sobre cómo el número de derechos productivos por licitarse afecta a los incentivos de firmas incumbentes para disuadir entrada.

Nuestro análisis se relaciona con el tema general de ventajas de competencia a favor de firmas incumbentes y sus incentivos para disuadir entrada de nuevos rivales (e.g., Dixit, 1980; Spence, 1977, 1979). En concreto, este trabajo desarrolla un modelo teórico sobre los incentivos de los incumbentes para disuadir

\footnotetext{
En el Anexo A.1 se explica que la autoridad sectorial optó por subastar la cuota global disponible en múltiples lotes o derechos de pesca precisamente porque pensaba que de esa forma aumentarían las posibilidades de entrada de firmas más pequeñas a esta industria.
} 
entrada vía estrategias de oferta en subastas secuenciales de múltiples derechos de pesca. Las subastas que se analizan corresponden a subastas orales de precio ascendente del tipo inglesas. Se supone que los competidores tienen información perfecta en cada fase de subasta. En este contexto informacional, subastas de sobre cerrado y de segundo precio producen resultados idénticos que subastas de precio ascendente (o inglesas).

En términos de literatura relacionada, Gilbert y Newbery (1982; G\&N en adelante) es un trabajo seminal que analiza el incentivo de un monopolio que posee la patente de un producto para disuadir entrada en la siguiente innovación de producto. El monopolista invierte en patentar una segunda innovación tecnológica (lo cual es modelado como una decisión estática) que es un sustituto cercano de su producto. En este modelo el monopolista siempre patenta primero el segundo producto, ${ }^{2}$ porque escoge una mayor inversión en I+D. ${ }^{3} \mathrm{El}$ beneficio que obtendría el potencial entrante por patentar el nuevo producto siempre será el beneficio obtenido en un mercado duopólico, dada una ventaja (exógena) de primer movimiento a favor del monopolista. Así, dado que el beneficio de una firma monopólica es mayor que el beneficio total de los duopolistas (como usualmente ocurre con el beneficio total de la industria cuando se produce entrada en un contexto no cooperativo), la valoración de una nueva patente para el monopolista incumbente será siempre mayor que la valoración del potencial entrante.

Trabajos posteriores extienden la intuición desarrollada en G\&N (1982) a subastas de múltiples licencias de producción. Así, Krishna (1993) argumenta que la venta secuencial de múltiples licencias (o unidades de capacidad) incrementa la posibilidad de entrada. En este modelo un monopolista comparte el mercado con pequeños competidores, siendo todos éstos tomadores de precios. Los potenciales entrantes, en caso de entrar, sólo pueden llegar a ser parte del grupo de firmas pequeñas.

Cuando la valoración del monopolista por cada nueva unidad de capacidad es positiva y creciente en el nivel de unidades adicionales de capacidad, disuadir entrada en las primeras etapas elevará el costo de disuasión en las siguientes. Así, en estos casos ocurrirá entrada en las fases iniciales de la secuencia de venta de licencias y disuasión exitosa de entrada sólo en la última fase de la secuencia de ventas. ${ }^{4}$ En este modelo sólo el monopolista incumbente posee poder de mercado, independientemente del resultado en las subastas. Así, entrada ocurrirá en tanto ello sólo cause una erosión limitada en las ganancias del incumbente.

2 Chen (2000) generaliza para los casos en que un producto y otro sean sustitutos estratégicos o bien complementos estratégicos, obteniendo que el resultado central de G\&N (1982) se mantiene, en general, sólo en el último caso.

3 Este trabajo considera que para patentar el nuevo producto se debe realizar una inversión, la que desarrolla quien tiene la mayor disposición a pagar, invirtiendo la segunda valoración más alta, i.e., un resultado equivalente al que se obtendría si el derecho se licitase en una subasta tipo Vickrey). Existe una única instancia de licitación y el derecho de producción es irrestricto (i.e., una vez adquirido, no impone una restricción productiva relevante).

4 Este resultado supone que las licencias en venta secuencial son de tamaño idéntico o creciente. Por el contrario, si el tamaño de las licencias aún por venderse cayese en forma suficientemente rápida, no ocurriría entrada. 
Trabajos posteriores extienden el análisis a casos con múltiples incumbentes (lo que es más relevante al caso que motiva a este trabajo). Rodríguez (2002) analiza un contexto de subastas secuenciales de $\mathrm{L}>1$ licencias de calidad homogénea. En cada subasta se vende una licencia de valor permanente. Cada licencia permite participar en un mercado oligopólico que ocurre inmediatamente después de completada la secuencia de L subastas. En la fase postsubasta, los entrantes también disfrutan de poder de mercado, i.e. las licencias adquiridas no implican restricción productiva relevante en este mercado. Así, la entrada de nuevos rivales puede producir una erosión más radical en las ganancias de los incumbentes, relativo a Krishna (1993). Ello explica que, en algunos casos, alguno o varios de los incumbentes puedan decidir disuadir todo intento de entrada. Rodríguez (2002) sólo considera la posibilidad de que los incumbentes usen estrategias no cooperativas para disuadir entrada.

En este modelo se puede generar entrada cierta en cada subasta mediante el artificio de imponer un límite superior a la erosión de ganancias del incumbente ante la entrada de un nuevo rival. Bajo ese supuesto, cuando existen $\mathrm{N} \geq 2$ incumbentes al inicio de la primera subasta, los incumbentes nunca logran disuadir entrada, porque el gasto en disuadir entrada tiene características de bien público. Mientras que si existe un único incumbente inicial, la posibilidad de disuadir entrada depende negativamente del número de licencias por subastarse. Esto último se relaciona con el mensaje general en Rodríguez (2002): ocurrirá entrada, en forma repetida, en tanto exista un número suficientemente grande de licencias en venta.

En contraste, Hoppe et al. (2006) argumentan que un mayor número de licencias en venta no necesariamente inducirá mayor entrada. En este modelo se subastan simultáneamente múltiples licencias, las que pueden tener distintas calidades y por las cuales compiten -de forma no cooperativa- múltiples incumbentes y potenciales entrantes. ${ }^{5}$ Se deduce que ofertar un mayor número de licencias puede incluso facilitar estrategias de coordinación (no necesariamente colusorias) entre los incumbentes para disuadir entrada. Sin embargo, la relación entre el número de licencias en venta y el número de incumbentes juega un rol clave. Por ejemplo, cuando se vende una única licencia y existen al menos dos incumbentes, existe una probabilidad positiva de entrada; pero si el número de licencias iguala al de incumbentes, no ocurre entrada. Este trabajo presenta un breve análisis sobre la posibilidad de que ocurra colusión entre los incumbentes para disuadir entrada. Para ello, considera el caso de una única licencia en venta y además presume la viabilidad de colusión perfecta entre los incumbentes para lograr éxito disuasivo pleno.

Este último trabajo es el más cercano a nuestro modelamiento. No obstante, ambos trabajos presentan varias diferencias en relación con un conjunto de supuestos relevantes. Al respecto, el modelo en el presente trabajo busca contribuir

$5 \quad$ Las licencias pueden diferir en calidad según el grado de sustitución (por el lado de la demanda) que ellas presenten en relación con las licencias bajo propiedad de los incumbentes. Por otro lado, se asume que los incumbentes utilizan estrategias simétricas y se consideran sólo equilibrios en estrategias mixtas. Así, cada incumbente define en forma probabilística su oferta por cada licencia, resultando de ello, en general, una probabilidad positiva de entrada. 
a entender aspectos específicos del caso en estudio. Por ello, asumirá que los derechos subastados son homogéneos y que su tamaño productivo depende de una cuota global de nivel exógeno. Asimismo, analizará la posibilidad de disuasión colusiva de entrada considerando explícitamente el caso de múltiples derechos de pesca en venta.

La sección 2 describe hechos relevantes del caso de estudio que motiva el modelo teórico. La sección 3 presenta la notación y supuestos del modelo. Las secciones 4 y 5 analizan el caso de disuasión de entrada, primero considerando la venta de un único lote y luego subastas de múltiples lotes. La sección 6 presenta conclusiones. Los Anexos ofrecen información complementaria.

\section{Caso de Estudio}

Esta sección describe aspectos relevantes sobre las barreras a la entrada y estructura de mercado en la industria del bacalao de profundidad, y luego ofrece un breve resumen de los resultados más relevantes, para efectos de este trabajo, en la serie de subastas anuales.

\subsection{Barreras de entrada en la pesca industrial del Bacalao de Profundidad}

Primero, la pesca industrial de esta especie ocurre en un número bastante limitado de zonas en el mundo; fundamentalmente en áreas del Pacífico sur-austral (sectores de la zona económica exclusiva (ZEE) de Chile y aguas circundantes (australes) internacionales), en zonas del Atlántico sur-austral y sur-antártico (sectores de las ZEE de Uruguay, Argentina, Malvinas, aguas bajo jurisdicción de la CCAMLR, ${ }^{6}$ y en aguas internacionales) y en algunos sectores del océano Índico sur/austral-occidental. En cada una de ellas prevalecen restrictivas regulaciones de entrega de licencias y cuotas de pesca. Según la FAO, ${ }^{7}$ a inicios de los años 2000 las capturas mundiales de esta especie bordeaban las 34 mil toneladas, con casi un tercio de ellas obtenidas en aguas chilenas.

Segundo, los barcos que operan en esta pesquería son intensivos en capital (cada uno con un costo de reemplazo de unos US\$ 5 millones), representando en gran medida un costo hundido. Por un lado, utilizan equipamiento de pesca muy específico. Aunque es técnicamente posible ajustarlos para otras artes de pesca, esta opción no es económicamente factible (Bravo, 2001). Por otro lado, desde fines de 1991 la mayoría de las pesquerías industriales en Chile están sujetas a regulaciones que restringen el acceso, pudiendo operar en ellas sólo barcos con permisos de pesca para cada una. Por último, los buques que operan en esta pesquería se enfrentan a similares restricciones de entrada en el resto del mundo, en caso que deseasen operar en otras zonas con similar interés comercial.

\footnotetext{
6 Organización multipaíses para administración pesquera y fines de investigación, bajo la potestad de la Convención para la Conservación de Recursos vivos marinos en la región Antártica, de la cual Chile es país miembro.

7 Catarci (2004)
} 
Nótese que el efecto restrictivo de las dos barreras previas de entrada, sobre la oferta de bacalao a nivel mundial, se potencia por las distintas temporadas (estacionalidades) de pesca que tienden a prevalecer en algunos de los más importantes caladeros de pesca de esta especie a escala global.

Una tercera barrera de entrada proviene de la escala mínima eficiente de operación en esta industria. Ella típicamente requiere realizar, por un lado, operaciones de pesca diversificadas en distintas especies y, por otro, inversiones de valor específico para crear redes de comercialización hacia y dentro de los mercados de exportación. Todo ello demanda períodos de implementación en los cuales las firmas pesqueras puedan ganar la confianza de comercializadores mayoristas en los mercados de consumo final. Esta necesidad de construir confianza y reputación es requisito frecuente en la comercialización de productos del mar, dada la existencia de importantes asimetrías de información relacionadas a la perecibilidad y calidad heterogénea del producto final (sea en términos de su frescura o técnica de congelado). Los costos de transacción y riesgos comerciales que surgen de lo anterior incentivan a que, sobre todo en la comercialización mayorista de productos pesqueros, predominen pocos y grandes agentes comercializadores, cuya escala de operación actúa como señal de reputación creíble (Doeringer y Terkla, 1995; Geirsson y Trondsen, 1991; Arnason, 2003; Peña y Vespa, 2008). Y, como veremos, junto a la alta concentración en la fase de comercialización internacional, en esta industria además predominan estructuras corporativas con integración vertical, sea de jure o de facto (vía restricciones contractuales), entre los comercializadores mayoristas internacionales y los agentes extractivos.

\subsection{Estructura de mercado}

Relacionado con lo anterior, desde hace más de una década en Chile ha existido un número reducido y estable de empresas incumbentes en la pesca industrial del bacalao de profundidad (véase Tabla 1). Estas empresas suelen tener integración vertical, o bien contratos de largo plazo sujetos a diversas restricciones verticales, con un número reducido de comercializadores mayoristas internacionales, cada uno con operaciones normalmente país -o región- específicas (Fernández, 2008; Peña y Vespa, 2008).

Así, los más importantes productores chilenos de bacalao han logrado establecer relaciones duraderas con redes específicas de distribución y comercialización en los principales mercados de destino final (Estados Unidos, Japón y la Comunidad Europea). En cada uno de estos mercados predominan unos pocos comercializadores mayoristas de gran tamaño, los que desarrollan estrategias de diferenciación de producto vía posicionamiento de valor de marca (Peña y Vespa, 2008).

La participación en el mercado mundial de las principales empresas que pescan bacalao en Chile no se limita al tercio de las capturas mundiales de esta especie que ocurren en aguas chilenas. Una proporción predominante de estas firmas forman parte de conglomerados pesqueros multinacionales y todas ellas también desarrollan capturas en el resto de los principales caladeros de pesca de esta especie en el mundo (i.e., poseen licencias y cuotas de pesca en las zonas bajo control de la CCAMLR, en las ZEEs de Argentina y de Uruguay y, además, 
pescan bacalao en diversas áreas de aguas internacionales). ${ }^{8}$ Estas empresas son parte de un reducido número de firmas que operan a escala mundial, pescando en distintos caladeros y países, y que venden su producción vía redes integradas de distribución y comercialización, cada una con inversiones específicas para diferentes mercados de destino.

Por el lado de la demanda, la producción de bacalao de profundidad -sea en formato fresco o congelado- no tiene sustitutos cercanos en otros peces de carne blanca. En este tipo de productos pesqueros, el bacalao de profundidad es, por lejos, la especie con mayor valor comercial. Así, por ejemplo, al año 2002 un filete de bacalao de profundidad costaba en Estados Unidos en torno a 9 US\$/libra, mientras que, y considerando los siguientes peces de carne blanca con mayor valor comercial, el filete de orange roughy costaba 4,2 US\$/lb, 3,5 US\$/lb el de haddock y 3 US\$/lb el de turbot (El Periódico de Acuicultura, Pto. Montt, diciembre de 2004).

A pesar de lo concentrado de la oferta mundial, junto con las opciones imperfectas de sustitución por el lado de la demanda, podría pensarse que los pocos grandes productores/comercializadores de bacalao no pueden ejercer poder de precios en los mercados de producto final, dadas las restrictivas regulaciones de cuotas de pesca vigentes para esta especie, lo que -eventualmente- les podría impedir controlar estratégicamente sus volúmenes de venta. Sin embargo, existen dos fuentes de información que plantean dudas sobre la validez de esta última hipótesis.

Primero, en ninguno de los años del período 1993-2002 los adjudicatarios de cuotas de pesca en Chile usaron el 100\% de las cuotas obtenidas vía subasta. El porcentaje promedio de uso en este período, a nivel agregado en la pesquería licitada, fue $72,6 \%$ del tonelaje total subastado de derechos de pesca (según registros oficiales de Subpesca). En algunos de esos años se usó en torno al 80-95\% del tonelaje total adjudicado vía subastas, mientras que en otros se usó incluso menos del $50 \%$ del tonelaje de pesca vendido. Segundo, algunas ONGs ambientalistas, apoyadas por representantes de agencias reguladoras nacionales, han planteado que varias de las principales empresas que participan en la pesca mundial del bacalao de profundidad, y que han participado en las subastas aquí analizadas, ejercerían arbitraje estratégico con las cuotas de pesca adquiridas en distintas jurisdicciones (siendo estas cuotas válidas sólo para pescar en determinadas zonas de pesca; Catarci, 2004). Así, el portfolio de cuotas adquiridas se podría usar, entre otras posibilidades, para justificar -en caso de ser sometidos a investigación in situ-capturas obtenidas en forma ilegal en otras zonas del mundo (ISOFISH, 1999).

En definitiva, y a partir del conjunto de argumentos y evidencias presentadas, en este trabajo se asumirá que las empresas incumbentes en Chile en la pesca industrial del bacalao de profundidad forman parte de un mercado oligopólico a

$8 \quad$ Las operaciones de pesca en aguas chilenas tienen una fuerte estacionalidad: ellas ocurren entre los meses de septiembre a febrero. En los meses restantes, la flota migra a pescar a distintos caladeros, algunos en aguas internacionales y otros en sectores bajo control de la CCAMLR (Peña y Vespa, 2008). 


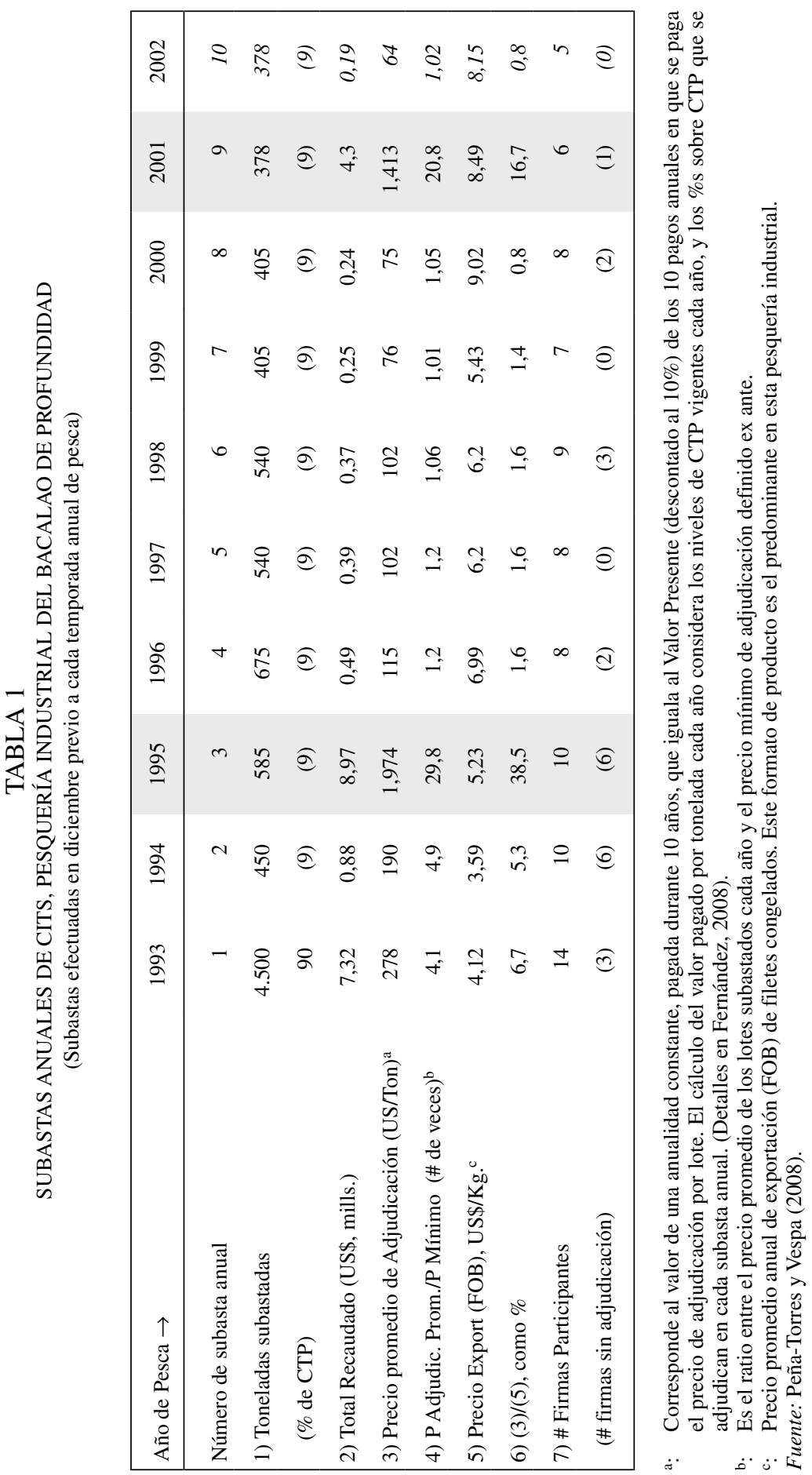


nivel mundial, en donde actúan muy pocos oferentes y cuyas operaciones de pesca están integradas con la fase de distribución y comercialización en los mercados de destino final de su producción. Se asumirá, además, que estos operadores integrados poseen poder de precios en sus mercados de venta final, dadas las importantes barreras de entradas que existen en esta industria, las imperfectas posibilidades de sustitución por el lado de la demanda y la evidencia que sugiere que las cuotas de pesca no necesariamente serían factores limitativos de las decisiones óptimas de oferta en el mercado mundial del bacalao de profundidad.

\subsection{Resultados del Proceso de Subastas}

El Anexo 1 ofrece un resumen de las reglas y procedimientos de las subastas en análisis. Esta sección detalla los resultados de la secuencia de subastas anuales, centrándose en aquellos aspectos que sirven de motivación para el modelo teórico que este trabajo desarrolla.

En las dos subastas con intento de entrada de un nuevo rival (uno distinto en cada ocasión), ${ }^{9}$ el precio promedio de adjudicación de los lotes subastados fue sustancialmente mayor, relativo a los precios promedio observados en el resto de los años. En la primera subasta con intento de entrada de un nuevo rival (tercera subasta anual), el precio promedio de adjudicación fue 1.974 US\$/ton, i.e. 16 veces superior al precio promedio de adjudicación en las subastas sin intento de entrada de nuevos rivales a esta industria (ver Tabla 1). ${ }^{10}$ En la segunda subasta con intento de entrada de un nuevo rival (novena subasta anual), otra vez el precio promedio de adjudicación fue manifiestamente superior al de las otras subastas anuales.

Al respecto, la fila (6) de la Tabla 1 permite constatar este aumento en los valores de adjudicación en las tercera y novena subastas, aumentos que distan de coincidir con cambios similares en los precios de exportación del principal producto procesado en esta pesquería (la mayoría de la producción de esta pesquería se exporta). Asimismo, en ninguno de los dos años con intento de entrada ocurrió algún cambio regulatorio, o en otra fuente de reducción relevante en los costos asociados (e.g, precio del petróleo) a este negocio pesquero, que permitan

9 En ambas ocasiones el nuevo rival era una empresa dedicada a la captura de otras especies, sin experiencia en la captura, ni menos en la comercialización internacional del bacalao de profundidad. Así, ambas empresas debían realizar inversiones específicas, tanto para ingresar a redes específicas de comercialización internacional como para adecuar o comprar buques con las artes de pesca requeridas en esta pesquería. En la tercera subasta anual la nueva empresa que participó fue Iquique-Guanaye S.A., perteneciente a un grupo económico con experiencia sólo en negocios pesqueros tipo commodity y cuya venta internacional es muy diferente a la del bacalao de profundidad. En la novena subasta anual participó un empresario local de la XII Región, que tampoco tenía experiencia alguna en la captura ni comercialización de peces como el bacalao de profundidad.

10 Esta comparación considera el precio promedio de adjudicación (US\$/ton de derecho anual de pesca) de las subastas ocurridas para los años de pesca 1993-2002, excluyendo las temporadas 1995 y 2001. 
explicar el muy significativo incremento en los precios de adjudicación de los derechos de pesca subastados en esos dos años.

Para efectos de completar el contexto de discusión, en lo que sigue se proporciona mayor información sobre los resultados observados en la serie de subastas anuales que ocurrieron entre diciembre de 1992 y diciembre de 2002. En la primera subasta anual participaron 14 empresas, de las cuales 11 se adjudicaron al menos un lote. Estas 11 empresas coinciden con aquellas que ya capturaban bacalao en forma previa al inicio del sistema de subastas. La primera subasta resultó en precios de adjudicación que en promedio fueron 4 veces superior al precio mínimo definido ex-ante. Esta subasta fue especialmente relevante porque en ella se subastó el $90 \%$ de la cuota global anual (CTP). Así, existía especial interés en adjudicarse lotes que permitiesen a las empresas consolidar sus operaciones en esta pesquería.

En la segunda subasta anual, el precio promedio de venta de las licencias de pesca fue casi un tercio inferior al precio promedio del año anterior (Tabla 1); pero aun así fue prácticamente 5 veces superior al correspondiente precio mínimo de venta.

Cuando se produce el primer intento de entrada de un nuevo rival (tercera subasta anual), los precios de adjudicación de los lotes subieron en forma espectacular: el precio promedio de venta (US\$/ton) fue 10 veces superior al promedio del año anterior y 30 veces superior al correspondiente precio mínimo de venta. El Gráfico 2 reporta los precios de adjudicación, junto con la respectiva empresa adjudicataria, de cada uno de los 10 lotes vendidos en esta tercera subasta anual. Nótese que, en este primer intento de entrada, el total de firmas participantes en esa subasta (i.e., eventuales competidores independientes) fue idéntico al de la subasta del año anterior. Así, el alza espectacular en el precio promedio de adjudicación de los lotes vendidos en la tercera subasta no puede interpretarse simplemente como el resultado de una mayor presión de competencia fruto del aumento en el número total de rivales.

En la cuarta subasta anual, el precio promedio de adjudicación (expresado en US\$/ton. de derecho de pesca) claramente disminuyó, siendo sólo $20 \%$ superior al correspondiente precio mínimo de venta. A partir de esta subasta, y hasta la octava, se mantuvieron precios de adjudicación muy cercanos al correspondiente precio de reserva (ver Tabla 1).

Por último, el Gráfico 3 reporta los precios de venta en las subastas de las temporadas de pesca de los años 2000 y 2002, siendo éstas representativas de los precios promedio de adjudicación observados en las subastas del período 1997-1999. Este Gráfico también muestra, en claro contraste, los precios de venta significativamente más altos obtenidos en la novena subasta anual, ${ }^{11}$ en la cual ocurre el segundo intento de entrada por parte de un nuevo rival. Nuevamente no es posible explicar esta significativa alza en los precios de adjudicación como la simple consecuencia de un aumento en el número total de rivales en la subasta anual (véase Tabla 1).

11 El precio de venta del sexto lote vendido en esta subasta es claramente una anomalía. No tenemos información que permita dar una explicación clara al respecto. 


\section{GRÁFICO 1}

PRIMERA SUBASTA ORDINARIA

(Año de pesca 1993)

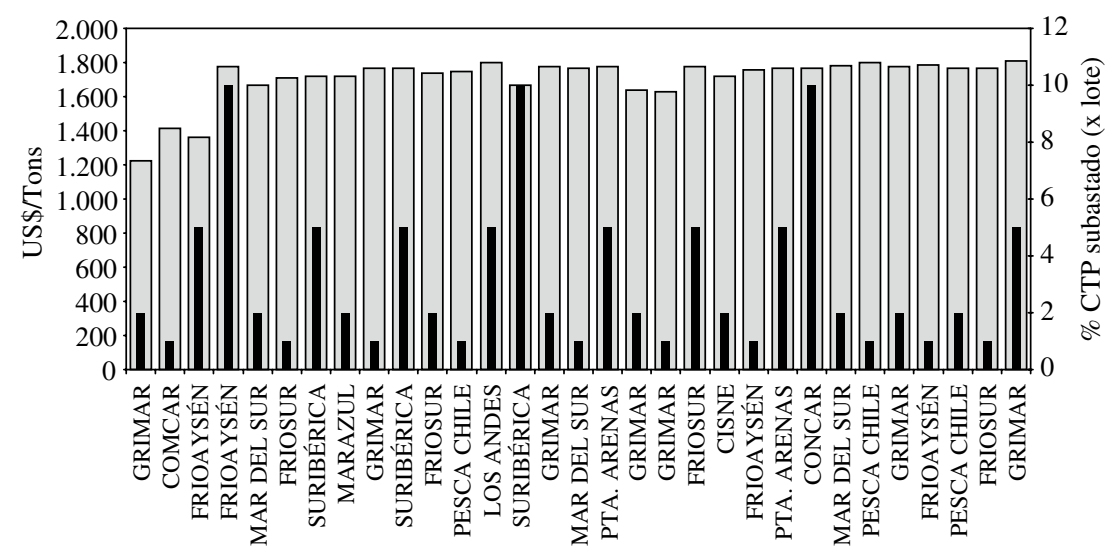

Empreas adjudicatarias en orden de subasta

Precio de cada lote subastado (US\$/Tons) $\square$ \% subastado en cada lote

\section{GRÁFICO 2}

TERCERA SUBASTA ORDINARIA

(Año de pesca 1995)

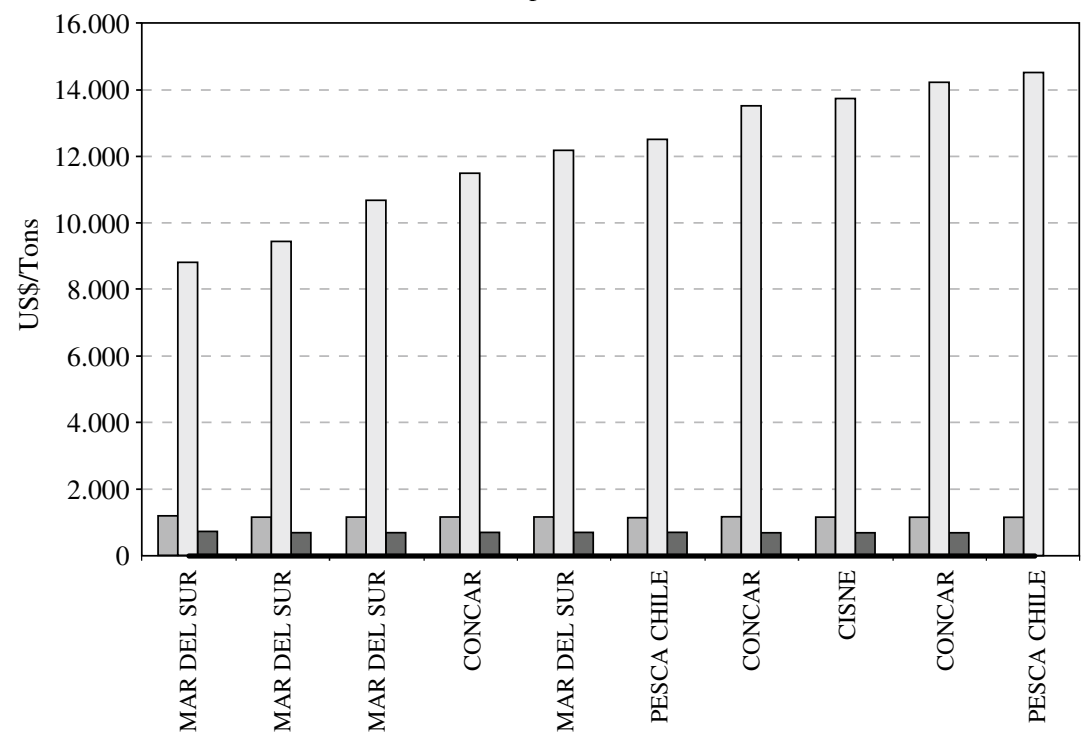

Empresas adjudicatarias de cada lote subasta 1995

P. Adjudicación (1994) $\square$ P. Adjudicación (1995)

P. Adjudicación (1996) — P. Piso (1995) 


\section{GRÁFICO 3 \\ NOVENA SUBASTA ORDINARIA \\ (Año de pesca 2001)}

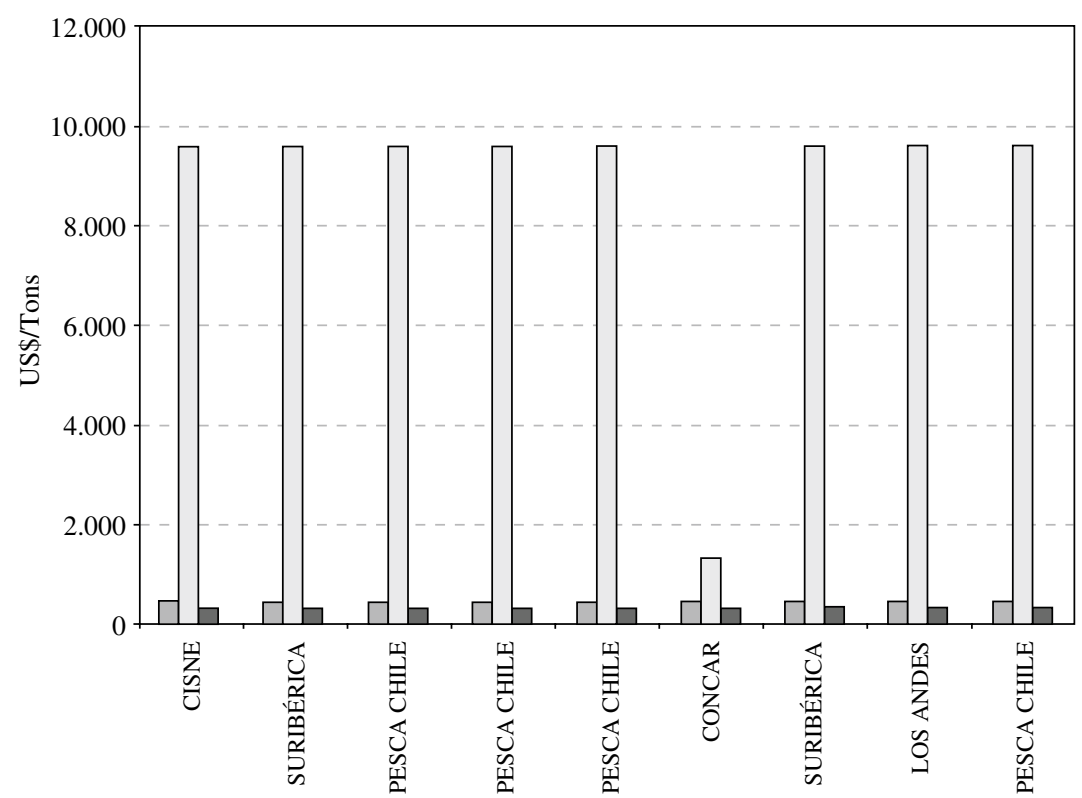

Empresas adjudicatarias 2001

Fuente: Elaboración propia a partir de información de Subpesca.

Notas:

(1) Los años graficados se refieren a años de pesca. La subasta de cada año de pesca se realiza en diciembre del año anterior.

(2) Los precios de adjudicación reportados en los gráficos 1-3 se refieren al valor presente descontado al $10 \%$ del total de derechos de pesca adquiridos en cada lote (i.e., válidos para un período de 10 años).

Dado lo hasta aquí argumentado, es dable entonces deducir que el único cambio realmente relevante y común, a los dos años de subasta con notorios incrementos en los precios de adjudicación de los derechos subastados, dice relación con los correspondientes intentos de entrada de un nuevo competidor (uno distinto cada vez) a esta industria. Así, lo relevante de analizar es por qué, asociado a estos intentos de entrada, las firmas incumbentes estuvieron dispuestas a pagar precios sustancialmente más altos (por tonelada) por los derechos adquiridos en esos dos años. Como alternativa a la hipótesis de una defensa colusiva de rentas extranormales por parte de los incumbentes, el modelo a continuación analizará condicionantes paramétricos de la posibilidad que los incumbentes hayan estado dispuestos a pagar, en forma no cooperativa, para disuadir la entrada de un nuevo rival a esta industria. 


\section{Modelo: Notación y Supuestos BÁSicos}

Se representa el comportamiento de $\mathrm{N} \geq 2$ firmas que participan en una secuencia de subastas inglesas. Las firmas compiten por comprar $\mathrm{L} \geq 1$ lotes homogéneos que se venden secuencialmente; cada lote representa derechos de pesca que las firmas acumulan para participar en la última etapa en un mercado Cournot, en donde se comercializa un bien homogéneo. Todos los participantes poseen información perfecta. ${ }^{12}$ Finalmente, y por simplicidad, se asume que los derechos de pesca subastados no son transables. ${ }^{13}$

$\mathrm{Al}$ inicio del proceso de subastas existen I $\geq 1$ firmas incumbentes; estas firmas ya poseen derechos de pesca y pueden participar en la última etapa Cournot sin necesidad de adquirir ningún lote; el supraíndice i denota al incumbente i. Existe también un número $\mathrm{E}$ de potenciales entrantes, que no tienen derechos de pesca al inicio de las subastas y necesitan adquirir lotes para participar en el mercado Cournot. Se asume $\mathrm{E}=1$ y el supraíndice e denota al potencial entrante. (El caso con $\mathrm{E}>1$ no ofrece intuiciones adicionales sobre los hechos estilizados que motivan a esta discusión).

Al final de la subasta de L lotes, en la cual participan $\mathrm{N}$ firmas $(N=I+1)$, se define el número de participantes $z \leq N$ que compite en el mercado Cournot postsubasta.

El proceso de subasta comienza con la licitación del lote 1 y sigue secuencialmente hasta el lote L. Por simplicidad, se escriben las estrategias de las firmas como si participaran en una subasta de sobre cerrado de segundo precio (a la Vickrey), la que bajo información perfecta genera los mismos pagos que una subasta oral de precio ascendente, tipo inglesa (Riley y Samuelson 1981, Krishna, 2002, Hoppe et al., 2006). Así, las estrategias de los participantes en la subasta se escriben como un perfil de mejores respuestas a la puja más alta en cada subasta (sin contar la propia), resultando ganadora la firma que puje más alto, comprometiéndose a pagar el valor de la segunda puja más alta. La regla para resolver empates es: si un incumbente empata con el entrante, gana el incumbente; y si existen dos o más incumbentes empatados entre sí, gana uno de

12 En la industria modelada no parecieran existir asimetrías significativas de información entre las firmas pesqueras rivales. La competencia imperfecta que prevalecería en esta industria, al menos en las fases de distribución y comercialización mayorista de la producción, podría tener otras fuentes de poder de mercado (e.g., véase Anderson, 2003; Doeringer y Terkla, 1995).

13 Fernández (2008) desarrolla una variante del modelo aquí presentado en el cual las firmas acumulan, vía compras en una (única) subasta secuencial de L lotes, toneladas de pesca que comercializan postsubasta en un mercado Cournot con bienes diferenciados, cuyos niveles de demanda son desconocidos al momento de la subasta, conociéndose entonces sólo la distribución de un parámetro que indica el nivel de demanda (suponiendo información simétrica para todos los competidores). Luego de la subasta, los participantes conocen el verdadero nivel de demanda y ajustan la cantidad que adquirieron en las subastas transando sus derechos de pesca. Dado que el valor esperado de las demandas, al momento de la subasta, es idéntico para todos los competidores y siendo todos ellos neutrales al riesgo, el pago esperado por ellos en la subasta secuencial resulta equivalente a los pagos que obtienen cuando participan en un mercado Cournot sin riesgo y de bien homogéneo. 
ellos con probabilidad $1 / k$, donde $\mathrm{k}$ es el número de incumbentes empatados (véase Hoppe et al., 2006).

Sea $s_{l}^{h}$ la puja más alta que la firma j observa para el lote (sin considerar la propia). El supraíndice $\mathrm{h}$ indica si la puja más alta fue realizada por una firma incumbente $(\mathrm{h}=\mathrm{i})$ o una entrante $(\mathrm{h}=\mathrm{e}) . b_{l}^{j}$ denota la puja que realiza la firma $\mathrm{j}$ para el lote $l$. En el mercado Cournot cada firma j tiene costos marginales constantes e idénticos $c \geq 0$, cada una produciendo $q_{j}(n)$. La producción total de la industria es $Q=\sum_{j=1}^{n} q_{j}$ y la función de demanda inversa es $P(Q)=a-Q$, siendo $a>c$ y $\mathrm{P}(\mathrm{Q})$ el precio del producto. Para competir en el mercado Cournot, la firma entrante debe incurrir en un costo hundido $\mathrm{F}>0$, pagable sólo una vez (al momento de adquirir su primer lote en las subastas). La escala mínima viable de operación se denota $q^{M I N}(F)$.

La capacidad de producción de cada firma depende de los derechos de pesca que posea. La restricción para las firmas incumbentes es $q_{i}^{R}=L_{i} \cdot q_{l}+x_{i}$, y $q_{e}^{R}=L_{e} q_{l}$ para la firma entrante. $L_{j}$ es el número de lotes que la firma $\mathrm{j}$ adquiere en la secuencia de subastas, $q_{l}$ las toneladas de pesca a que da derecho cada lote $l$ (todos los lotes son idénticos) y $x_{i}$ los derechos de pesca (toneladas) que tiene el incumbente $\mathrm{i}$, previo al inicio de las subastas. Todas las firmas incumbentes son simétricas $\left(x_{i}=x\right)$.

En la etapa Cournot los rivales no necesariamente usarán todos los derechos de pesca que posean. Cada firma produce la cantidad que maximiza su beneficio, condicional a su capacidad de producción. Así, en la etapa Cournot pueden existir dos tipos de firmas: las restringidas (con restricción de producción activa) y las no restringidas (con restricción de producción inactiva).

$\mathrm{Al}$ momento de adquirir un nuevo lote, la valoración de cada firma por ese lote dependerá de si su restricción de capacidad en la etapa Cournot es activa o no. Si una firma acumuló al momento de la licitación del lote $l$ una cantidad de derechos de pesca menor que la cantidad óptima Cournot (i.e., tiene una restricción activa a ese momento), valorará el lote $l$ según la ganancia que produzca su venta en la fase Cournot. Si sus derechos de pesca al momento de licitación son mayores que la cantidad óptima Cournot (firma no restringida), su valoración por el lote $l$ no vendrá por su venta en la fase Cournot (tal venta sería subóptima), sino que dependerá de que otro rival adquiera el lote y luego venda la pesca a que tal lote da derecho en la fase Cournot, reduciendo así el precio de equilibrio en dicho mercado.

Se asumirá que: (i) todas las firmas incumbentes son siempre no restringidas en la etapa Cournot, i.e. aun si no adquiriesen ningún lote en las subastas, sus $\mathrm{x}>0$ toneladas iniciales son suficientes para producir el óptimo Cournot. ${ }^{14}$

14 Bajo este supuesto, una posible racionalidad para que el regulador pesquero mantenga una cuota de pesca total anual mayor a la escala óptima Cournot de producción de las firmas incumbentes es entender a tal política como un límite ante posibles incrementos en la pesca agregada, dada la posibilidad de entrada de nuevas firmas. Otra posibilidad es que el regulador crea que el nivel de la cuota es el óptimo productivo, pero enfrente problemas significativos de fiscalización para hacer cumplir dicha restricción. 
Nótese que la posible validez empírica de este supuesto no puede ser descartada a partir de la evidencia citada en la sección 2. Por otro lado, (ii) la firma entrante será siempre restringida, aun si adquiriese todos los lotes en venta. Así, los incumbentes no tendrán ningún incentivo a competir entre ellos por adquirir un lote. Su única razón para adquirir un lote será disuadir la entrada de nuevos rivales, cuya entrada bajaría el precio de mercado de cada tonelada de pesca, al aumentar la cantidad total ofrecida en la etapa Cournot. En consecuencia, para los incumbentes el valor de los lotes subastados será cero en caso que un potencial entrante no participe en la subasta; en caso contrario, el valor del lote será la pérdida de ganancias para el incumbente que ocasionaría su compra por parte del potencial entrante.

Si los incumbentes necesitaran adquirir un cierto número de lotes para ser no restringidos en la fase Cournot, previo a la adquisición de esos lotes su comportamiento en las subastas sería similar al del entrante. En ese caso la única diferencia que persistiría entre ambos tipos de firma sería la mayor valoración por lote de los incumbentes, dado que éstos ya han pagado el costo hundido F.

En este modelo la única forma de que exista disposición a pagar de los incumbentes para evitar la entrada de un nuevo rival, suponiendo que los incumbentes son rivales independientes que no mantienen acuerdo colusorio alguno entre ellos, es que estas firmas sean agentes no restringidos. Si fuesen restringidos, su nivel de producción Cournot sería del todo independiente del número de rivales en ese mercado y, por tanto, su valoración para disuadir entrada sería cero. Permitir que las firmas incumbentes pudiesen mutar, a lo largo de la secuencia de subastas, desde ser inicialmente agentes restringidos y luego pasar a ser firmas no restringidas introduciría complicaciones innecesarias al modelo. Por ello, tal posibilidad se excluye vía supuesto.

Por otro lado, si se aceptase la posibilidad que los incumbentes fuesen agentes restringidos, entonces la única posible explicación, en este modelo, para el significativo aumento observado en los precios de los lotes vendidos en las dos subastas anuales con intento de entrada, es que tales alzas de precios reflejarían el valor de proteger rentas extranormales de los incumbentes, logradas mediante un acuerdo colusorio para disminuir la competencia entre ellas al momento de adquirir los lotes licitados. Esta deducción supone que otros condicionantes de la valoración por lote se mantienen inalterados en los 2 años con intento de entrada, respecto del resto de años con subastas, lo que es razonable suponer dada la evidencia presentada en la sección 2.

En relación con la firma entrante, si se permitiera que esta firma pudiera transformarse a través de compras en las subastas en un rival Cournot no restringido, ello generaría dos efectos: Primero, tal entrada generaría una mayor caída en el precio Cournot de equilibrio, versus si el entrante fuese un rival restringido. Así, permitir que el potencial entrante pudiese entrar como un rival no restringido generaría a los incumbentes un incentivo aun más fuerte, ceteris paribus, para disuadir su entrada (similar intuición se deriva en Krishna, 1993 y Rodríguez, 2002). Segundo, ocurrida la entrada del nuevo rival como una firma no restringida, su comportamiento en las subastas sería estratégicamente idéntico al de los otros incumbentes. Así, para lograr parsimonia en el análisis 
se mantendrá inalterado el supuesto de que la firma entrante siempre es de tipo restringida.

Los supuestos previos requieren imponer ciertas condiciones sobre $x$ y $q_{l}$. Sea $q^{*}\left(I, L_{e}\right)$ la cantidad de pesca a partir de la cual los lotes adquiridos en las subastas se convierten en una restricción inactiva en la maximización del beneficio Cournot. Para que todos los incumbentes sean siempre no restringidos, sea $x \geq q^{*}(I, 0)$. Por otro lado, para asegurar que el potencial entrante tenga una valoración positiva por cada lote y que en la etapa Cournot participe como un agente restringido, sea $q^{M I N}(F)<q_{l}<\frac{q^{*}(I+1,0)}{L}$. Esto es, (i) la escala mínima de operación será menor que las toneladas de pesca contenidas por lote y (ii) los derechos de pesca acumulados en el total de $\mathrm{L} \geq 1$ lotes por subastar será menor que la cantidad necesaria para convertirse en un agente no restringido.

$\mathrm{Si}$ la firma que compra un nuevo lote fuese incumbente, los otros incumbentes saben que ella no aumentará la cantidad total en el mercado Cournot, y por ello les resultará indiferente esa compra. Pero si tal compra la realiza un nuevo entrante, éste usará toda su cuota disponible en la fase Cournot. Entonces los incumbentes valorarán ese lote en el monto que caerían sus beneficios, dada la caída en el precio de equilibrio Cournot. La valoración de cada incumbente por el último lote subastado será por lo tanto: ${ }^{15}$

$$
V_{L}^{i}= \begin{cases}\Pi^{i}(Q)-\Pi^{i}\left(Q+q_{l}\right)>0 & \text { Si lote L es comprado por entrante } \\ \Pi^{i}(Q)-\Pi^{i}(Q)=0 & \text { Si lote L es comprado por otro incumbente }\end{cases}
$$

donde $\Pi^{\mathrm{i}}(\mathrm{Q})$ es la ganancia Cournot, dado el volumen de oferta Q. Por su parte, la firma entrante valorará cada lote por el beneficio que pueda obtener en la etapa Cournot con las toneladas adquiridas. Así, su valoración por el lote $l$ será:

$$
V_{l}^{e}=\Pi^{e}\left(l \cdot q_{l}\right)-\Pi^{e}\left((l-1) \cdot q_{l}\right)
$$

Para efectos de analizar cómo cambian los incentivos de los incumbentes para coludirse en las subastas cuando puede participar un nuevo rival, se introducen dos supuestos adicionales que permiten repetir infinitas veces este juego (o proceso secuencial) de subasta, siendo la estructura de cada subjuego idéntica a lo ya descrito:

15 Note que cada incumbente sabe, al momento de la subasta del lote $l<L$, el efecto que tendrá su respectiva puja en el resultado de las futuras subastas de lotes adicionales (dada la estructura informacional en este modelo, cada jugador decide sus estrategias óptimas usando inducción hacia atrás). Por lo tanto, cada incumbente considerará los resultados esperados en esas futuras subastas al decidir la valoración del lote $1<\mathrm{L}$ (dado que conoce el efecto que tendría la adquisición de un lote cualquiera por parte del entrante, sobre la cantidad total de lotes que dicho entrante podría lograr alcanzar al iniciar la etapa Cournot). Así, la valoración de un lote l cualquiera no corresponde -en un sentido estricto- a la expresada en (1). Esta expresión sólo es válida para la subasta del último lote subastado. 
(A1) La cantidad $\mathrm{x}>0$ de derechos de pesca que tienen los incumbentes al inicio de cada subjuego es invariante en el tiempo. Así, (i) estos derechos no pierden valor en el tiempo, (ii) no existe traspaso de inventarios de capturas, desde un subjuego a otro y (iii) los derechos adquiridos vía subasta sólo sirven para el mercado Cournot inmediatamente posterior.

(A2) Al inicio de cada subjuego de venta secuencial de $\mathrm{L} \geq 1$ lotes, el potencial entrante debe hundir un costo $\mathrm{F}>0$ para participar en tal proceso de subasta.

Con estos dos supuestos puede replicarse el subjuego descrito (i.e., subasta de L lotes y el posterior mercado Cournot) infinitas veces, lo que permitirá analizar los beneficios de una eventual colusión entre las firmas incumbentes durante su participación en el proceso de subastas.

En la siguiente sección se resuelve el modelo considerando que en cada subjuego se licita un único lote. Esto permite derivar de manera sencilla tres resultados de interés: (i) La existencia de un efecto free rider al disuadir la entrada de un nuevo rival, (ii) el límite que impone este efecto a la capacidad de coludirse entre los incumbentes para disuadir entrada y (iii) las condiciones necesarias para que un potencial entrante logre adquirir el lote en venta. En la sección 5 se resuelve el modelo considerando la venta secuencial de L lotes en cada subjuego. Allí se analizará: (a) cómo la divisibilidad del volumen total de producción por subastarse (que se modela parametrizando el número de lotes en venta bajo el supuesto que el volumen total de producción por subastarse se mantiene constante) afecta a la posibilidad de entrada de un nuevo rival en un contexto no colusorio y (b) en qué medida la divisibilidad del volumen total de producción por subastarse afecta los incentivos de los incumbentes para coludirse en las subastas para así disuadir entrada.

\section{Subasta de 1 Lote}

En esta sección se analizan las condiciones para que, en el caso de $\mathrm{L}=1$, los incumbentes disuadan la entrada cuando: (i) $V^{i} \geq V^{e}$ y por lo tanto no se requiera ningún tipo de coordinación entre los incumbentes para disuadir entrada y (ii) $V^{i}<V^{e}$ y por lo tanto la única opción de disuadir entrada sea vía algún mecanismo de coordinación entre los incumbentes.

Un aspecto clave en la valoración por lote de cada incumbente $\left(V^{i}\right)$ es que el gasto en disuadir entrada, que realice alguna de estas firmas, tendrá propiedades de bien público: si algún incumbente invierte en disuadir entrada, todos los restantes se benefician de igual forma con ese gasto, existiendo incentivos, por lo tanto, para que estas firmas actúen como free riders. A continuación se demuestra que, dado $V^{i} \geq V^{e}$, no será equilibrio Nash en estrategias puras que todos los incumbentes empaten y luego se dividan entre ellos el costo de disuadir entrada. En todos los equilibrios Nash subsistirá el efecto free rider.

Proposición 1 (Efecto Free Riding; L = 1). Si (i) E=1 = L, (ii) los incumbentes actúan de forma no coordinada y (iii) $V^{i} \geq V^{e}$, entonces en estrategias puras existirán múltiples equilibrios Nash en los cuales un incumbente cualquiera 
asume todo el costo de disuadir la entrada, mientras los demás se benefician de la disuasión sin incurrir en gasto alguno.

Demostración. Dado que cada subjuego es independiente del resto, en cada uno la función de pagos de los incumbentes es idéntica. Un incumbente representativo j al inicio de la subasta del único lote en licitación, tendrá en cada subjuego la siguiente función de pagos:

$$
w^{j}= \begin{cases}\Pi^{j}(Q)-s^{h} & \text { si } b^{j}>s^{i \neq j} \text { ó } \quad b^{j} \geq s^{e} \\ \Pi^{j}(Q)-\frac{1}{k} \cdot\left[s^{i}\right] & \text { si } b^{1}=b^{2}=b^{3}=\ldots b^{j}=\ldots=s^{i} \\ \Pi^{j}(Q) & \text { si } b^{j}<s^{i \neq j} \text { y } \quad s^{i \neq j} \geq s^{e} \\ \Pi^{i}\left(Q+q_{l}\right) & \text { si } s^{i}<s^{e}\end{cases}
$$

donde $k$ es el número de incumbentes empatados en la puja más alta $s^{i}$. La función de pagos para el potencial entrante será:

$$
w^{e}= \begin{cases}\Pi^{e}\left(Q+q_{l}\right)-s^{i} & \text { si } b^{e}>s^{i} \\ 0 & \text { si } b^{e} \leq s^{i}\end{cases}
$$

Entonces, no será equilibrio que más de un incumbente gaste en disuadir la entrada; ello porque para un incumbente cualquiera sus pagos son mayores si otro disuade la entrada: $\Pi^{j}(Q)>\Pi^{j}(Q)-\frac{1}{k}\left[s^{i}\right]$.

Por otro lado, será equilibrio que un incumbente cualquiera compre el único lote subastado, dado que los pagos para este incumbente por disuadir la entrada (por sí solo) son mayores o iguales que el pago por permitir la entrada $\left(\Pi^{j}(Q)-b^{e} \geq \Pi^{j}\left(Q+q_{l}\right)\right)$. Ello, porque la estrategia de equilibrio del entrante es pujar exactamente su valoración, $\Pi^{e}\left(Q+q_{l}\right)$, y dado que:

$$
V^{i} \geq V^{e} \Leftrightarrow \Pi^{i}(Q)-\Pi^{i}\left(Q+q_{l}\right) \geq \Pi^{e}\left(Q+q_{l}\right)
$$

La Proposición 1 ofrece la siguiente intuición. Dado que el lote subastado sólo tiene valor para los incumbentes cuando éste puede ser adquirido por un nuevo rival, el beneficio para los incumbentes de que al menos uno de ellos adquiera el lote subastado tiene características de bien público. Ello por cuanto, asociado al gasto en disuasión, no existe consumo rival ni posible exclusión de los restantes incumbentes del beneficio resultante. Así, cuando la valoración por lote de cada incumbente sea mayor o igual que la del entrante, sólo uno 
de ellos invertirá en disuadir entrada, beneficiando a todos los demás, los que actuarán como free riders. ${ }^{16}$

Nótese que, manteniendo las condiciones (i) y (iii) de la Proposición 1, jamás podría ocurrir colusión entre los incumbentes para efectos de compartir el gasto en disuadir la entrada de un nuevo rival, dado que en este contexto no existirán castigos creíbles ante eventuales desvíos del acuerdo colusorio. Naturalmente, no resultaría creíble la amenaza de que algún incumbente permitiese, como castigo a quien se desviase del eventual acuerdo, que el entrante adquiera el lote en subasta. Por lo mismo, la presencia de un potencial entrante, en este contexto específico, no afecta en nada los incentivos a coludirse en la subasta.

¿Qué sucede cuando cada incumbente no puede por sí solo disuadir la entrada del potencial nuevo rival $\left(V^{i}<V^{e}\right)$ ? En este caso podría ser viable sostener un acuerdo colusorio, para cofinanciar el gasto en disuasión. La Proposición 2 explicita el mínimo factor de descuento, cuando $V^{i}<V^{e}$, que posibilita la colusión en una serie infinita de subastas, entre un grupo mínimo de $n$ incumbentes (i.e., el que permite que para cada incumbente que participe en dicho acuerdo colusorio el beneficio de estar coludido, en cada subjuego, sea mayor que el beneficio de competir como agente Cournot), para efectos de disuadir la entrada de un nuevo rival. Este resultado permitirá luego analizar cómo cambia la sustentabilidad de dicho acuerdo colusorio cuando la licitación del mismo total de derechos (toneladas) de pesca ocurre mediante la venta de múltiples lotes $(\mathrm{L}>1)$.

Proposición 2 (Colusión entre incumbentes; cada subjuego con L=1). Si (i) Existe una secuencia infinita de subjuegos idénticos e independientes entre sí, donde cada subjuego corresponde a la subasta de un único lote $(L=1)$, siendo ésta seguida inmediatamente por una instancia de competencia Cournot, en la cual las firmas utilizan los derechos de producción, (ii) $V^{i}<V^{e}$ (iii) $n \cdot V^{i}>V^{e}$ $y($ iv) $1<n \leq I$ incumbentes establecen un acuerdo colusorio mediante el cual comparten equitativamente el costo total de la disuasión en cada subasta, bajo la amenaza de castigar la ocurrencia de al menos un desvío de dicho acuerdo mediante la reversión para siempre a estrategias que permiten la entrada de un nuevo rival, entonces el factor mínimo de descuento que sostiene la colusión entre los $n$ incumbentes será:.

$$
\underline{\delta}=\frac{V^{e}}{n \cdot V^{i}}
$$

16 Nótese que al ser todos los incumbentes iguales existirán tantos equilibrios de Nash como número de incumbentes que participen en la subasta. En caso de permitirse estrategias mixtas, cada uno de los incumbentes disuadiría la entrada de un nuevo rival con una determinada probabilidad, ocurriendo por lo tanto entrada con la probabilidad complementaria (e.g., véase Hoppe, 2006). 
Demostración. Ver Anexo A.2.

La Proposición 2 plantea un mecanismo para sostener un acuerdo colusorio que tiene por objeto reducir el costo que cada incumbente debe solventar para tener éxito en disuadir entrada. Usando este artificio lógico, se deduce entonces una condición paramétrica $(\delta(n)$; con $\mathrm{L}=1)$ que caracteriza la sustentabilidad de dicho acuerdo.

El mínimo factor de descuento calculado en la Proposición 2 muestra que los incentivos de los incumbentes para coludirse se incrementan (ceteris paribus, en el contexto estudiado) en la medida que la valoración del entrante por el lote subastado sea menor y se aproxime a la valoración de los incumbentes, hasta que eventualmente $V^{i} \geq V^{e}$, en cuyo caso el efecto free rider hace imposible que los incumbentes puedan coludirse.

A continuación se identifican condiciones necesarias en la competencia postsubasta para que, bajo el supuesto de $\mathrm{L}=1$, la valoración del entrante por dicho lote sea mayor que la del incumbente $\left(V^{i}<V^{e}\right)$. Si alguna de las condiciones necesarias para que $V^{i}<V^{e}$ no se cumple, entonces necesariamente $V^{i} \geq V^{e}$, en cuyo caso la disuasión de entrada del potencial entrante es posible de lograr en forma no coordinada, i.e. sin colusión entre los incumbentes. Identificar estas condiciones permite analizar, en particular, el efecto de: (a) el tamaño productivo del derecho en venta (i.e., las toneladas totales de pesca a que da derecho), (b) el nivel de los costos fijos (hundidos) de entrada, en relación a una proxy indirecta del posible margen (unitario) de ganancia oligopólica, i.e. (a-c) >0, y (c) el número de incumbentes rivales en el mercado postsubasta.

Proposición 3 (Disuasión de Entrada No Coordinada; L=1): Si se realiza una serie de subastas, cada una con $L=1$ y seguida de una etapa de competencia Cournot, entonces $V^{e}>V^{i}$ si y sólo si se cumplen copulativamente las siguientes tres condiciones:

(i)

$$
I>1
$$

$$
\begin{gathered}
\frac{F}{(a-c)^{2}}<\frac{I^{2}-2}{[(1+I) \cdot(2+I)]^{2}} \\
q_{l}>\frac{(a-c)(I-1)-\sqrt{(a-c)^{2}(I-1)^{2}-4 \cdot I \cdot F(I+1)}}{2 I}
\end{gathered}
$$

Demostración. Ver Anexo A.3.

La siguiente Figura 1 grafica las valoraciones de un incumbente representativo y del potencial entrante por el lote subastado en función de la cantidad de toneladas subastadas, para valores dados del costo hundido $F$ (que afecta la posición vertical de la función de valor del entrante) y del número $I$ de incum- 


\section{FIGURA 1}

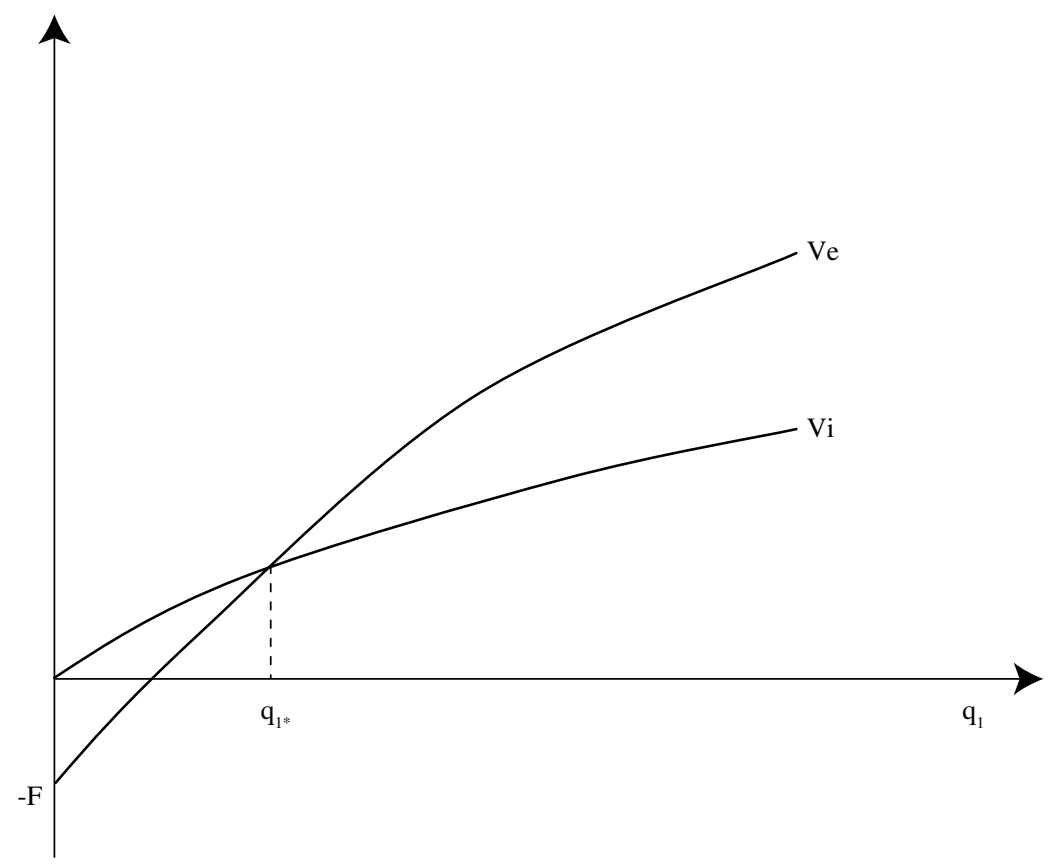

bentes rivales que participan en el mercado postsubasta (el valor de I afecta la pendiente de ambas funciones de valoración, con mayor fuerza en el caso de $V^{i}$ ), tales que aseguren que ambas funciones se igualen para una cantidad $\mathrm{q}_{1}^{*}>0$ de toneladas subastadas. Así, cumpliéndose las condiciones (i) y (ii) de la Proposición 3, ceteris paribus, necesariamente $V^{e}>V^{i}$ en la medida que la cantidad subastada sea mayor que $q_{l}$.

En relación a las subastas realizadas para los años de pesca 1995 y 2001, las Proposiciones 1 y 3 , si bien están planteadas para la simplificación $\mathrm{L}=1$, sirven para motivar la posibilidad de que la disuasión de entrada que se observó en ambos años pudo haber ocurrido como resultado de estrategias no cooperativas entre las firmas incumbentes, y no necesariamente fruto de un acuerdo colusorio entre ellas.

En el contexto hasta ahora analizado, la ocurrencia de disuasión de entrada, sin colusión entre los incumbentes, habría requerido que se incumpliera al menos una de las tres condiciones señaladas en la Proposición 3. Así, habría requerido, por ejemplo: (a) que se incumpliera la condición (i) en esta Proposición. Ello podría ocurrir en tanto las firmas incumbentes estuviesen perfectamente coludidas en el mercado postsubasta, de forma que de facto $\mathrm{I}=1$, o bien que derechamente la industria fuese un monopolio natural, en cuyo caso la ventaja de costo a favor del incumbente, dado $F>0$, siempre permitiría al monopolista evitar la entrada de un nuevo rival; o bien (b) que se incumpliese la condición (ii) en la Proposición 3, de forma tal que el costo de entrada $\mathrm{F}$ fuese suficientemente alto en relación a la rentabilidad esperada del negocio oligopólico (Cournot), 
esta última aproximada por una proxy indirecta del posible margen unitario de ganancia oligopólica, i.e. (a-c) >0, aumentando así la ventaja de competencia a favor de los incumbentes; o (c) que se incumpliese la condición (iii) en la Proposición 3, de forma tal que el tamaño productivo del lote subastado fuese suficientemente pequeño. Al respecto, nótese que un mayor valor de $\mathrm{q}_{1}$, ceteris paribus, tenderá a estar asociado con mayores ganancias para el entrante y, por ello, con un mayor valor de $\mathrm{V}^{\mathrm{e}}$. Mientras que la pérdida de ganancias Cournot para cada incumbente y por lo tanto el valor de $\mathrm{V}^{\mathrm{i}}$, dado un valor de $\mathrm{q}_{1}$ y la caída resultante en el precio del equilibrio Cournot ante la entrada de un nuevo rival, tenderá a ser menor a mayor valor de I, en cuyo caso se favorecerá el cumplimiento de la condición (i) en la Proposición 3, y así la posibilidad de entrada del nuevo rival.

Otra deducción interesante a partir de las condiciones identificadas en la Proposición 3 es que cuando el número de firmas incumbentes sea igual o menor que 2 (véanse las condiciones i y ii), y aún si no existen costos fijos hundidos $(\mathrm{F}=0)$, el (los) incumbente(s) siempre logrará(n) disuadir la entrada del potencial entrante. Este resultado se debe a la ventaja de primer movimiento, a favor del incumbente, que surge de la posesión de una cantidad inicial de derechos de pesca $(x>0)$, tal que el incumbente siempre es un competidor no restringido en el mercado postsubasta. Ello limita las utilidades del potencial entrante, en caso que lograse entrar, como máximo a las ganancias de un duopolista, mientras que el incumbente representativo se mantendrá como monopolista (o como duopolista, si $\mathrm{I}=2$ ) si disuade la entrada. Así, la pérdida de beneficios del incumbente, si ocurre entrada al mercado Cournot, será mayor (o a lo más igual) que las posibles ganancias del entrante; en cuyo caso nunca ocurrirá entrada en nuestro modelo. Este resultado reproduce lo obtenido en G\&N (1982), en donde un monopolista incumbente siempre evita la entrada de un nuevo rival, en un juego de entrada que ocurre sólo una vez.

De haberse cumplido las tres condiciones identificadas en la Proposición 3, y bajo el contexto de análisis hasta aquí asumido, esta Proposición plantea que la disuasión de entrada observada en las subastas para los años de pesca 1995 y 2001 no podría haber ocurrido como resultado de un equilibrio no-cooperativo. Para poder analizar este resultado en un contexto de mayor generalidad, a continuación se analiza cómo varían las condiciones para disuadir entrada cuando se subasta una cantidad total dada de derechos de pesca en un mayor número de lotes, esto es $\mathrm{L}>1$.

\section{Subasta Secuencial de $\mathrm{L}>1$ Lotes}

Esta sección analiza cómo afecta, a la capacidad de los incumbentes para disuadir entrada, el hecho que una cantidad total dada de derechos (toneladas) de pesca por licitarse sea subastada en un mayor o menor número de licencias de pesca. Para resolver el problema de maximización de los incumbentes y del entrante en una serie de subastas secuenciales de $\mathrm{L}>1$ lotes, se definen las estrategias de las firmas en función de distintos estados o contingencias. Estos estados o historias son el número de lotes que haya adquirido el entrante con 
anterioridad a la actual subasta de un nuevo lote. Así, si al momento en que se inicia la licitación del lote $l$ el entrante ya posee 3 lotes, la historia en $l$ será $h_{l}=3$. El conjunto de historias posibles es $H_{l}=(0,1,2, \ldots, l-1)$, que indica todas las posibles historias que puede enfrentar un jugador al momento de inicio de la subasta del lote $l$. El pago esperado por el incumbente representativo $\mathrm{j}$ cuando se realiza la subasta $l$ depende de $E^{j}\left[h_{L+1} \mid h_{l}\right]$, i.e. del número esperado (en $l$ ) de lotes que vaya a adquirir el entrante al final de la subasta de los L lotes. Así, en la etapa L+1 de competencia (mercado Cournot) el número de lotes adquiridos por el entrante será $h_{L+1}$, lo cual es estimado por cada incumbente -al momento de la subasta del $l$-ésimo lote-condicional a la cantidad de lotes que el entrante ya tenga acumulados hasta ese momento.

Una estrategia para el incumbente j será un vector $\left(b_{1}^{j}, b_{2}^{j}, b_{3}^{j}, \ldots b_{L}^{j}, q_{j}\left(h_{L+1}\right)\right)$, en donde $\mathrm{q}_{\mathrm{j}}($. $)$ denota la producción Cournot del incumbente j y $b=\left(b_{1}^{j}, b_{2}^{j}, b_{3}^{j}, \ldots b_{L}^{j}\right)$ es función del valor esperado (en la etapa $l$-ésima) $E^{j}\left[h_{L+1} \mid h_{l}\right]$. La noción de equilibrio que se utiliza permite resumir el número de subjuegos de modo que los participantes de la subasta elijan su estrategia en función del estado que enfrentan $\left(h_{l}\right)$, sin importar en qué orden el entrante adquirió los distintos lotes que posea. La función de transición entre $h_{t}$ y $h_{t+1}$ será $\Lambda_{t+1}=f\left(h_{t}, b_{t}, s_{t}^{h}\right)$. Por último, la ley de probabilidad condicional que asegura independencia de las estrategias con respecto al tiempo será la siguiente: $E^{j}\left[h_{l}=\theta \mid h_{l-1}=\omega\right]=E^{j}\left[h_{l+s}=\theta \mid h_{l+s-1}=\omega\right]$. Las estrategias así definidas corresponden a estrategias Markovianas y el concepto de equilibrio utilizado se denomina Equilibrio Markoviano Recursivamente no Dominado (sofisticación de un equilibrio markoviano perfecto; véase Rodríguez, 2002).

El beneficio que obtiene una firma incumbente $\mathrm{j}$ por la adquisición del l-ésimo lote será:

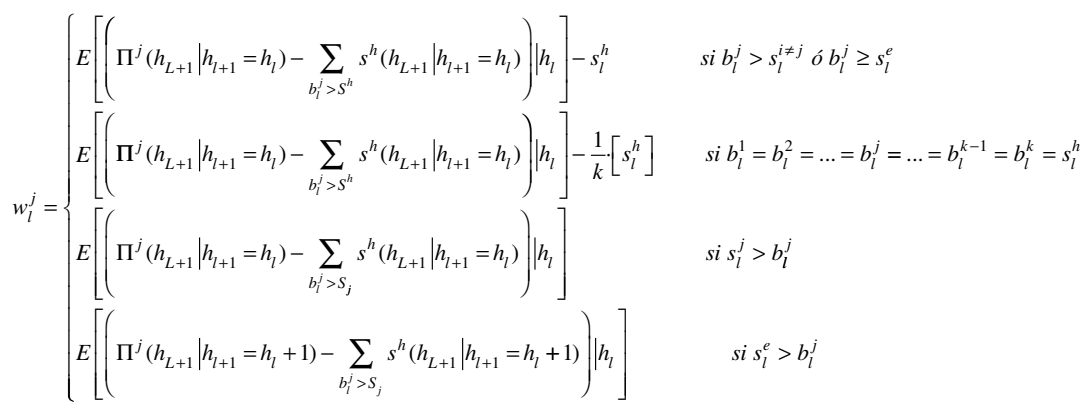

donde $\mathrm{k}$ denota el número de incumbentes que empataron en la puja máxima, mientras que $E\left[\Pi^{j}\left(h_{L+1} \mid h_{l+1}=\theta\right) \mid h_{l}\right]$ denota el beneficio esperado por la firma incumbente $\mathrm{j}$ al momento de la subasta $l$, dado que el entrante al momento de esa subasta tiene $h_{l}$ lotes y luego de dicha subasta tendrá $\theta$ lotes, con $\theta=\left\{h_{l}, h_{l}+1\right\}$. 
Por su parte, $E\left[\left(\sum_{b_{l}^{j}>S_{j}} s_{j}^{h}\left(h_{L+1} \mid h_{l+1}=\theta\right)\right) \mid h_{l}\right]$ denota los pagos esperados que deberá realizar la firma incumbente j si desea que en la última etapa se realice la historia $h_{L+1}$, tomando como dato que en la etapa $l$ la historia vigente era $h_{l}$ y que la historia vigente en la etapa $l+1$ sea igual a $\theta$.

A continuación se demuestra que licitar una cantidad total dada de derechos (toneladas) de pesca en múltiples $(\mathrm{L}>1$ ) lotes puede facilitar, en relación a subastar idéntica cantidad total en un único lote, que los incumbentes compartan de manera no colusiva el gasto total requerido para disuadir entrada; y ello, incluso en contextos de valoraciones relativas $\left(V^{i} / V^{e}\right)$ en los cuales es imposible disuadir entrada en forma colusiva cuando el mismo total de toneladas de pesca se licita en un único lote.

Para exponer esta idea, la siguiente Proposición 4 considera un contexto paramétrico tal que si $\mathrm{L}=1$ entonces $V^{i} \geq V^{e}$, siendo imposible bajo esta configuración paramétrica que los incumbentes se coludan para compartir el gasto total requerido para disuadir entrada. En este contexto se demuestra que, para el caso en que se vendan múltiples lotes tal que $\mathrm{I} \geq \mathrm{L}>1$, e imponiendo un límite máximo al número de veces que cada incumbente está dispuesto a disuadir la entrada de un nuevo rival (vía imponer un valor máximo sobre F), en todos los equilibrios Markovianos Recursivamente No Dominados (EMRND) L incumbentes compartirán de manera simétrica, y de forma no cooperativa, el costo total de la disuasión, turnándose para adquirir cada uno un lote (existiendo tantos equilibrios de este tipo como formas de turnarse sean posibles). ${ }^{17}$

Proposición 4 (Disuasión de Entrada vía Turnos; $I \geq L>1$ ). Sea $q_{l}=\frac{Q_{l}}{L}$, donde $q_{l}$ es la cantidad de derechos de pesca en cada lote, $Q_{l}$ la cantidad total (constante) subastada y $L>1$ el número de lotes. Asuma además que: (i) los incumbentes $(I \geq 2)$ y el entrante $(E=1)$ utilizan estrategias puras, (ii) si se licitaran las $Q_{l}$ toneladas totales en sólo un lote $(L=1) \Rightarrow V^{i} \geq V^{e}$ y (iii) cada incumbente no puede disuadir más de una vez a un entrante que desea adquirir su primer lote, en tanto se cumpla que $F<\frac{q_{l}}{(I+1)^{2}} \cdot\left(I \cdot\left(a-c-q_{l}\right)-q_{l} / 2\right)$, entonces, si $I \geq L \Rightarrow$ el potencial entrante no adquirirá ningún lote, ya que siempre un incumbente distinto disuadirá su entrada.

Una nota de cautela sobre la interpretación del siguiente resultado: Si bien se demostrará la existencia de equilibrios Nash no cooperativos como los descritos en la Proposición 4, cuesta imaginar como probable, en la práctica, que incumbentes simétricos tales que I > L, y que deciden simultáneamente, utilicen conjeturas como las que requieren los equilibrios descritos en la Proposición 4, sin que tengan algún mecanismo explícito de coordinación. (Al respecto, véase Hoppe et al., 2006, p. 378). 
Demostración: Ver Anexo A.4.

Equilibrios en donde la disuasión de entrada ocurre vía turnos entre los incumbentes son especialmente interesantes desde el punto de vista de los hechos estilizados. En los dos años de subasta con disuasión de entrada se observaron patrones de alternancia entre algunas de las empresas incumbentes, al momento de comprar los distintos lotes vendidos en cada año (al respecto, véanse los Gráficos 2 y 3). Sin embargo, un análisis más detallado sobre este último aspecto rebasa los desarrollos posibles en este trabajo. (Para más detalles al respecto, véase Peña y Vespa, 2008).

En la medida que se relaje el límite máximo impuesto sobre el valor del costo fijo F, establecido en el supuesto (iii) de la Proposición 4, aumentará el número de equilibrios no cooperativos en los que las firmas incumbentes pueden disuadir la entrada de un nuevo rival mediante sistemas de turnos no necesariamente simétricos; por ejemplo, y manteniendo el supuesto de estrategias puras, algunos incumbentes podrían disuadir la entrada más de una vez, mientras que otros en sólo una ocasión. Y en todos estos equilibrios no cooperativos nunca ocurrirá entrada, en tanto se cumpla I $\geq \mathrm{L}$.

Otro resultado de interés, en relación a la Proposición 4, es que al poder los incumbentes compartir el gasto total en disuadir entrada -producto de la venta de múltiples lotes tal que $I \geq L>1$, aumentan las posibilidades para disuadir entrada en forma no colusiva, relativo al caso de subastar el mismo total de toneladas de pesca en un único lote. Así, al aumentar la cantidad de lotes en venta, con $Q_{l}$ constante, la disuasión no colusiva de entrada se hace viable para un rango más amplio de valores paramétricos. En efecto, y a modo de ejemplo: en tanto $\mathrm{L}>1$, el resultado de disuasión no colusiva de entrada será ahora también viable para casos en los cuales si $\mathrm{L}=1$ entonces $V^{e}>V^{i}$, pero además se cumpla que $n \cdot V^{i} \geq V^{e}$, con $\mathrm{n} \leq \mathrm{I}$ y en donde $L=I>1$. Esta intuición se formaliza en el siguiente Corolario.

Corolario $4.1(L=I>1)$. Sea $q_{l}=\frac{Q_{l}}{L}$, donde $q_{l}$ es la cantidad de derechos de pesca en cada lote, $Q_{l}$ la cantidad total (constante) subastada y $L>1$ el número de lotes. Asuma que (i) si $L=1 \Rightarrow V^{e}>V^{i}$ y (ii) $\underline{n} \cdot V^{i}=V^{e}$, con $1<\underline{n} \leq I$ y (iii) $Q_{l} \leq(a-c) \cdot\left(\frac{I \cdot(I-2 \cdot \underline{n})+1}{I \cdot(I+1-\underline{n})-1}\right)>0$. Entonces, si se licitan las $Q_{l}$ toneladas (constantes) en $L=I>\overline{1}$ lotes, existirá al menos un Equilibrio Markoviano Recursivamente No Dominado (EMRND) en el cual cada incumbente adquiere un lote y por lo tanto no ocurre entrada.

Demostración: Ver Anexo A.5.

La intuición detrás del Corolario 4.1 es la siguiente: Considerando, por un lado, que (a) subastar $\mathrm{Q}_{1}$ toneladas de pesca en múltiples $(\mathrm{L}>1)$ lotes ofrece a los incumbentes la posibilidad de compartir el Costo Total de Disuadir Entrada 
$(C T D E)$ y, por otro lado, (b) centrándose en el caso particular en el cual la valoración agregada de $\underline{n} \leq \mathrm{I}$ incumbentes (respecto de la cantidad $\mathrm{Q}_{1}$ subastada) iguala a la correspondiente valoración del entrante, entonces dividir la cantidad $\mathrm{Q}_{1}$ subastada en un número $\mathrm{L}$ de lotes que sea equivalente o mayor que $\underline{n}>1$ permitirá que el costo que cada incumbente deba asumir, para cada uno adquirir un solo lote, sea menor que su respectiva valoración, evitándose de esta forma -y de manera no colusiva- la entrada de un nuevo rival.

Nótese que el resultado en el Corolario 4.1 impone una condición de máximo sobre el valor de $Q_{l}$. Esto se debe a que el $C T D E$ no necesariamente permanecerá constante para todo número $\mathrm{L} \geq 1$ de lotes en que $\mathrm{Q}_{1}$ se divida para efectos de su venta. Para lograr más intuición al respecto, en el siguiente Lema se identifican condiciones paramétricas tales que: (i) el valor del CTDE será creciente, constante o decreciente a medida que aumenta el número de lotes en venta $\mathrm{y}$, por otro lado, (ii) el valor del CTDE para el caso con L > 1 será mayor, igual o menor que el valor del $C T D E$ con $\mathrm{L}=1$.

Lema 4.2 (Costo Total de Disuadir Entrada con L $>1$ lotes). Sea $q_{l}=\frac{Q_{l}}{L}$, donde $q_{l}$ es la cantidad de derechos de pesca en cada lote, $Q_{l}$ la cantidad total (constante) subastada y $L>1$ el número de lotes. El Costo Total de Disuadir Entrada (CTDE) para los incumbentes, esto es el costo de adquirir las $Q_{l}$ de toneladas en venta $\left(L \cdot \Pi^{e}\left(Q+q_{l}\right)\right)$, será mayor (menor o igual) cuando $Q_{l}$ se subaste dividido en $L>1$ lotes, relativo al $\boldsymbol{C T D E}$ resultante cuando esas mismas $Q_{l}$ toneladas se licitan con $L=1$, en tanto se cumpla:

$$
L<(\geq) \frac{Q_{l}^{2}}{F \cdot(I+1)} .
$$

Asimismo, el $\boldsymbol{C T D E}$ que deberá pagar el conjunto necesario de incumbentes (tal que aseguren el éxito en disuadir entrada) será creciente (decreciente o constante) con respecto a aumentos en $L$ en tanto se cumpla:

$$
L<(\geq) \frac{Q_{l}}{\sqrt{F \cdot(I+1)}} .
$$

Demostración: Ver Anexo A.6.

El Lema anterior demuestra que para un rango de valores de $\mathrm{L}>1$, el CTDE aumenta conforme se hace más divisible el gasto en disuasión de entrada (i.e., a medida que L aumenta), aunque este aumento ocurre a tasa decreciente; existiendo de hecho un tramo a partir del cual el CTDE disminuye a medida que $\mathrm{L}$ sigue aumentando. La Figura 2 grafica la relación entre el $C T D E$ y L, para dos niveles de costo F. A medida que el valor de F cae, el CTDE aumentará, ceteris 


\section{FIGURA 2}

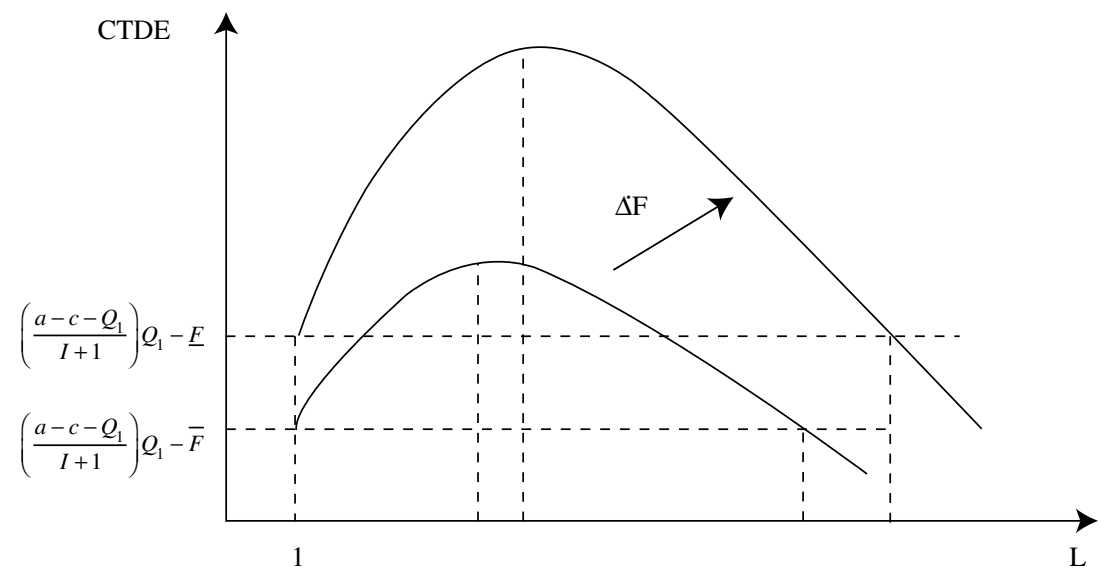

paribus, y además existirá: (a) un mayor rango de valores $\mathrm{L}>1$ para los cuales el $C T D E$ es creciente, como también (b) un mayor rango de valores $\mathrm{L}>1$ en los cuales el correspondiente $C T D E$ superará al $C T D E$ con $\mathrm{L}=1$.

Respecto al resultante costo de disuasión per cápita, i.e. el CTDE dividido por el número de incumbentes necesarios para tener éxito en disuadir entrada, y considerando el caso $\mathrm{I} \geq \mathrm{L}$, dividir las toneladas $\mathrm{Q}_{1}$ de pesca en venta en $\mathrm{L}>1$ (múltiples) lotes siempre implicará un menor gasto en disuasión per cápita (gasto que es igual a $\Pi^{e}\left(Q+q_{l}\right)$ ), relativo al costo de disuasión per cápita cuando $\mathrm{L}=1$. Lo anterior, porque $\Pi^{e}\left(Q+q_{l}\right)$ será siempre menor en tanto cada lote en venta sea más pequeño, lo que en este modelo necesariamente ocurrirá toda vez que el volumen total $Q_{1}$ de pesca se divida en un mayor número de lotes por subastar. En consecuencia, para $\mathrm{I} \geq \mathrm{L}$, es posible conjeturar que aumentos en $\mathrm{L}$ debieran tender a hacer más factible, ceteris paribus, un resultado de disuasión no colusiva de entrada.

¿Cómo se debiera comportar el costo de disuasión per cápita, a medida que aumenta L, cuando I < L? En este caso, el costo de disuasión per cápita será $(L / I) \cdot \Pi^{e}\left(Q+q_{l}\right)$. Así, el costo de disuasión per cápita se comportará en forma equivalente a cómo varíe el valor del CTDE, i.e. $L \cdot \Pi^{e}\left(Q+q_{l}\right)$, ante cambios en L, lo que se describe en la segunda parte del Lema 4.2. Nótese, en todo caso, y en relación con la función graficada en la Figura 2, que el valor de la función 'costo de disuasión per cápita' corresponderá al graficado en dicha Figura pero ahora dividido por I y que, además, el rango de valores posibles para L partirá en $\mathrm{L}=\mathrm{I}$. Por lo último, la función 'costo de disuasión per cápita' podría tener o no tener, según cuál sea el valor de $\mathrm{I} \geq 1$, un rango de valores crecientes a medida que L aumenta.

La siguiente Proposición 5 analiza cómo la posible divisibilidad de las toneladas $\mathrm{Q}_{1}$ en venta afecta a la factibilidad (sostenibilidad) de un acuerdo colusorio 
entre los incumbentes, cuyo propósito sea disuadir la entrada de un nuevo rival. Al igual que en el caso de la Proposición 2, el siguiente análisis excluye vía supuesto la existencia de costos de coordinación necesarios para alcanzar y mantener un acuerdo colusorio entre los incumbentes partícipes en él.

Proposición 5 (Acuerdo Colusorio, con L > 1 en cada subjuego). Sea $q_{l}=\frac{Q_{l}}{L}$, donde $q_{l}$ es la cantidad de derechos de pesca en cada lote, $Q_{l}$ la cantidad total (constante) subastada y L > 1 el número de lotes. Asuma además que: (i) los incumbentes $(I \geq 2)$ y el entrante $(E=1)$ utilizan estrategias puras, (ii) si se licitaran las $Q_{l}$ toneladas totales en sólo un lote: $(L=1) \Rightarrow V^{e}>V^{i}$, (iii) $Q_{l}>(a-c) \cdot\left(\frac{I \cdot(I-2 \cdot \underline{n})+1}{I \cdot(I+1-\underline{n})-1}\right)$, en donde $\underline{n}$ es tal que $\underline{n} \cdot V^{i}=V^{e}, y(i v) 1<n \leq I$ incumbentes se coluden para disuadir la entrada, con $n>\left(L \cdot \Pi^{e}\left(Q+q_{l}\right) / V^{i}\right),{ }^{18}$ mediante el siguiente mecanismo: Un incumbente cualquiera adquiere todos los lotes $(L>1)$ y después cada incumbente perteneciente al acuerdo paga proporcionalmente su parte en el gasto total CTDE. Si algún incumbente, de aquellos necesarios para sostener el acuerdo, se desvía al menos una vez del acuerdo (i.e. paga menos de lo acordado), entonces los restantes incumbentes miembros del acuerdo revierten sus respectivas estrategias a las compatibles con el equilibrio no cooperativo previo (Cournot), por lo que se produce entrada en todos los subjuegos sucesivos. Bajo estas condiciones, el mínimo factor de descuento que asegura la sostenibilidad del acuerdo colusorio descrito es: $\underline{\delta}=\frac{L \cdot \Pi^{e}\left(Q+q_{l}\right)}{n \cdot V^{i}}$.

Demostración: Ver Anexo A.7.

Nótese que en la Proposición 5, dado L > 1, el CTDE para los incumbentes coludidos será $L \cdot \Pi^{e}\left(Q+q_{l}\right)$, mientras que el correspondiente $C T D E$ en la Proposición 2 (cuando $\mathrm{L}=1$ ) será $\Pi^{e}\left(Q+Q_{l}\right)$. Por otro lado, el Lema 4.2 ha demostrado que existe un rango de valores $\mathrm{L}>1$ tal que el correspondiente CTDE será estrictamente mayor que en el caso $L=1$. Así, dados los valores de los factores mínimos de descuento deducidos en las proposiciones 2 y 5 (que en ambos casos equivalen a la razón entre el respectivo CTDE y $n V^{i}$ ), y en tanto la condición (i) del Lema 4.2 se cumpla con el signo de desigualdad $<(>)$, entonces subastar en $\mathrm{L}>1$ lotes una cantidad $\mathrm{Q}_{1}$ dada de derechos de producción dificultará (facilitará), ceteris paribus, la viabilidad de un acuerdo colusorio entre los incumbentes, según lo descrito en las Proposiciones 2 y 5 , en relación al caso cuando $\mathrm{Q}_{1}$ se subaste en un único lote. Una mayor 'dificultad' para coludirse equivale a que, con $\mathrm{L}>1$, el mínimo factor de descuento

18 Esta desigualdad se requiere para que el factor de descuento $\underline{\delta}$ sea menor que la unidad (i.e., que la correspondiente tasa mínima de descuento $\mathrm{r}$ sea positiva). 
que viabiliza el acuerdo colusorio sea mayor que el correspondiente al caso con $\mathrm{L}=1$ (suponiendo constante el número de incumbentes que participan en el acuerdo colusorio). O bien, ahora para un valor paramétrico dado de $\mathrm{r}>0$, que con $\mathrm{L}>1$ el número de incumbentes necesarios para viabilizar el acuerdo colusorio sea mayor que el necesario con $\mathrm{L}=1$.

\section{Conclusiones}

Algunas lecciones que resaltan del análisis desarrollado son:

(i) El gasto en disuasión exitosa de entrada puede llegar a tener características de 'bien público' para el grupo de firmas incumbentes; ello, en tanto la sumatoria de los valores de demanda del grupo total de firmas incumbentes, relacionados al total de derechos de producción en venta, supere al monto necesario para financiar, sea de forma no cooperativa o bien colusiva, el gasto total en disuasión. De lo anterior se deduce, por ejemplo, que la posibilidad de coludirse para disuadir la entrada de un nuevo rival sería del todo inviable, en tanto la pérdida de beneficios para el incumbente representativo, producto de esa entrada de un nuevo rival, sea mayor que la valoración del potencial entrante por participar en dicho mercado.

(ii) En este modelo, que la pérdida de beneficios que produce la entrada de un nuevo rival, para el incumbente representativo, sea mayor o menor que el beneficio de entrar para el potencial nuevo rival dependerá del nivel de: (a) concentración industrial en el mercado postsubasta (lo que en este modelo es proxy de la intensidad de competencia alcanzable en dicho mercado), (b) los costos hundidos de entrada (proxy de la ventaja de competencia a favor de las firmas incumbentes), y (c) la cuota global subastada y el grado en que ella se divida para efectos de su venta (lo que afecta directamente el valor de cada derecho productivo en venta). Así, por ejemplo, para valores paramétricos dados del número total de incumbentes y el monto de costos hundidos, aumentos en la cantidad total subastada harán más probable, todo lo demás constante, la entrada de un nuevo rival.

(iii) Respecto a la divisibilidad de los derechos de producción subastados, se ha obtenido que subastar una cierta capacidad de producción en múltiples licencias tiende a facilitar, por un lado, que los incumbentes puedan usar "algún mecanismo de coordinación" para compartir el costo total de disuadir entrada. En este trabajo, no todos los posibles mecanismos para compartir el gasto total en disuasión son, en un sentido de definición estricta, de naturaleza colusiva, i.e. que requieran de un "acuerdo real y consciente de voluntades para alcanzar el resultado de coordinación" (según lo ha definido Richard Posner). Sin embargo, también se ha argumentado que en varios de los posibles equilibrios no cooperativos que permitirían a un grupo de incumbentes compartir el gasto total en disuasión, resulta poco probable -desde un punto de vista práctico- que las firmas incumbentes, dada la forma como éstas han sido modeladas, coincidan en usar precisamente las conjeturas estratégicas necesarias para sostener dichos equilibrios. 
Por otro lado, también se ha demostrado que, para un rango de valores de número múltiple de lotes o licencias productivas en venta, aumentos en el número de lotes en venta pueden aumentar el costo total de disuadir plena o totalmente la entrada de un nuevo rival (Lema 4.2). Así, el efecto que pueda tener el vender un nivel dado de capacidad de producción en un mayor o menor número de licencias, sobre las posibilidades de entrada para nuevos competidores, dependerá finalmente de cómo se resuelva, en cada caso, el trade-off de incentivos resultante para las firmas incumbentes, en términos de disponer, por un lado, de una mayor facilidad para viabilizar formas de compartir el gasto total en disuasión y, por otro, enfrentar incrementos en el gasto total necesario para asegurar el éxito en disuadir entrada.

(iv) En relación a cómo posibles aumentos en el número de lotes en venta pudiesen afectar a los incentivos de los incumbentes para coludirse y así disuadir entrada, en este modelo el efecto depende de cómo esos aumentos cambien el costo total de disuasión de entrada, según se analizó en la Proposición 5.

Nótese que en todos los equilibrios derivados en los cuales ocurre disuasión de entrada, sea esto de forma no cooperativa o bien vía colusión, los incumbentes gastan recursos en evitar la entrada de un nuevo rival; y ello para defender la apropiación de rentas extranormales en el mercado oligopólico de competencia final, sin que dicho gasto genere -en el modelo desarrollado- ningún efecto positivo de bienestar social. En este sentido, las implicancias de eficiencia asignativa de los resultados de disuasión de entrada en este trabajo no difieren, en lo cualitativo, de las equivalentes implicancias de otros equilibrios oligopólicos analizados en trabajos clásicos sobre este tema (e.g., Dixit, 1980; Spence, 1977).

Por lo anterior, las razones que explican la ocurrencia de disuasión de entrada en el modelo analizado siempre involucran, en tanto ocurra disuasión, estrategias ilícitas de competencia por parte de los incumbentes. Ello por cuanto su objeto inequívoco consiste en impedir de forma artificial, i.e. sin efecto positivo alguno sobre el bienestar social, la entrada de un nuevo rival; y ello, por lo tanto, a costa de perpetuar la ocurrencia de pérdidas asignativas en el mercado final de competencia. En este sentido, y en tanto se acepte la motivación de los posibles supuestos y condiciones paramétricas que generan equilibrios con disuasión de entrada en este trabajo, nuestro análisis resalta la relevancia de desarrollar mayor análisis sobre los incentivos de competencia asociados a las reglas de subasta que se han seguido usando en Chile para licitar cuotas de pesca, tanto en la pesquería analizada como en otras de carácter industrial.

\section{REFERENCIAS}

Anderson, J.L. (2003). “The International Seafood Trade", Woodhead Publishing Limited, Abington, Cambridge U.K.

Anferova E, Vetemaa, M. y Hannesson, R. (2005). "Fish quota auctions in the Russian Far East: a failed experiment", Marine Policy, Vol. 29; 47-56.

Athey, S. y Levin, J. (2001). "Information and Competition in US Forest Timber Auctions", Journal of Political Economy, Vol. 109, No 2; 375-417. 
Baldwin, L.; Marshall, R. y Richard, J.-F. (1997). "Bidder collusion at Forest Service Timber Sales", Journal of Political Economy, Vol. 105, № 4; 657-699

Bravo, J. (2001). "Evaluación del Sistema de Cuotas Individuales Transferibles de Pesca, para el caso del Langostino Colorado y del Bacalao de Profundidad", Tesis para optar al grado de Magíster en Economía de Políticas Públicas, Instituto de Economía, PUC, Santiago.

Catarci, C. (2004). "World markets and industry of selected commercially aquatic species with an international conservation Profile", FAO Fisheries Circular-c990. Disponible en http://www.fao.org/DOCREP/006/Y5261E/ y5261e09.htm

Chen, Y. (2000). "Strategic Bidding by Potential Competitors: Will Monopoly Persist?", Journal of Industrial Economics, Vol. 48, № 2, 161-175.

Dixit, A. (1980). "The role of investment in entry-deterrence", Economic Journal, Vol. 90; 95-106.

Doeringer, P.B. y Terkla, D.G. (1995). “Troubled Waters: Economic Structure, Regulatory Reform and Fisheries Trade", University of Toronto Press, Toronto.

Fernández, G. (2008). “Disuasión de entrada vía subastas: free riding o colusión”, Tesis para optar al grado de Magíster en Economía, ILADES-Georgetown, $U A H$, Santiago.

Geirsson, M. y Trondsen, T. (1991). "Frozen cod products in the US market". En W. Schrank \& N. Roy (eds.), Econometric Modelling of the World Trade in Groundfish. Kluwer Academic Publishers, Canada.

Gilbert y Newbery (1982). "Preemptive Patenting and the Persistence of Monopoly", The American Economic Review, Vol. 72, № 3, 514-526.

González, E.; García, M. y Norambuena, R. (2001).“Changes in Fleet Capacity and Ownership of Harvesting Rights in the Fishery for Patagonian Toothfish in Chile", en FAO Fisheries Technical Paper 412, pp. 221-238.

Hendricks, K. y Porter, R. (1988). "An Empirical Study of an Auction with Asymmetric Information", The American Economic Review, Vol. 78, $\mathrm{N}^{\mathrm{o}} 5 ; 865-883$.

Hendricks, K. y Porter, R. (2007). "An empirical perspective on auctions”, ch. 32 in Handbook of Industrial Organization, Vol. 3; editors: M. Armstrong $\&$ R. Porter. Elsevier

Hoppe, H.; Jehiel, P. y Moldovanu, B. (2006). "License Auctions and Market Structure", Journal of Economics \& Management Strategy, Vol. 15, 371-396.

Huppert, D. (2005). "Capturing rents and recovering costs: the Geoduck management systems in Washington State and British Columbia", mimeo.

ISOFISH (1999). "The Chilean fishing industry: its involvement in and connections to the illegal, unreported and unregulated exploitation of Patagonian toothfish in the Southern Ocean" (www.isofish.org.au)

Klemperer, P. (2004). "Auctions: Theory and Practice", Princeton Univ. Press, Princeton, N.Y.

Klemperer, P. (2008). "Competition policy in auctions and "bidding markets", cap. 16 en P. Buccirossi (ed.), Handbook of Antitrust Economics, The MIT Press. 
Krishna, V. (1993). "Auctions with Endogenous Valuations of Monopoly Revisited", The American Economic Review, Vol. 83; 147-160.

Krishna, V. (2002): "Auction Theory”, Academic Press, Elsevier, San Diego/ California.

Lemaitre, C.; Rubilar, P.S.; Gebauer, P. y Moreno, C.A. (1991). "Regional Catch Analysis of Long-Line Fisheries of Dissostichus Eleginoides in Chile", Document WG-FSA-91/10 CCAMLR, Hobart, Australia.

Peña-Torres, J. (2002). "Debates sobre Cuotas Individuales: ¿Privatizando el mar, subsidios o muerte anunciada de la pesca extractiva en Chile?", Estudios Públicos 86, 183-222.

Peña-Torres, J; Bustos, J. y Pérez, C. (2006): "Mercados Informales y Control Vertical: Comercialización de Producción Perecible", Estudios Públicos 101, 239-282.

Peña-Torres, J. y Vespa, E. (2008). "Las subastas del Bacalao de Profundidad (Dissostichus Eleginoides)", Mimeo, Facultad Economía y Negocios UAH; Santiago, Chile.

Porter, R. y Douglas Zona, J. (1993). "Detection of Bid rigging in Procurement auctions", JPE 101 (June): 518-538.

Porter, R. (1995). "The role of information in US offshore oil and gas lease auctions", Econometrica 63 (1): 1-27.

Riley, J.G. y Samuelson, L. (1981).“'Optimal auctions”, AER 71: 381-392.

Rodríguez, G. (2002). "Auctions of licences and market structure”, Economic Theory 19, pp. 283-309.

Selten, R. (1975). "A reexamination of the perfectness concept for equilibrium points in extensive games", International Journal of Game Theory 4, pp. $25-55$.

Spence, A.M. (1977). "Entry, capacity, investment and oligopolistic pricing", Bell Journal of Economics, Autumn, 8: 534-544.

Spence, A.M. (1979). "Investment strategy and growth in a new market", Bell Journal of Economics, Spring, Vol. 10; 1-19.

Subpesca (2000). "Cuota Global Anual de Captura para la Pesquería de los Recursos Merluza del Sur y Congrio Dorado, año 2001”, Informe Técnico (R. Pesq.) No 73, Valparaíso.

Vetemaa, M.; Eero, M. y Hannesson, R. (2002). "The Estonian fisheries: from the Soviet system to ITQs and quota auctions", Marine Policy; Vol. 26; 95-102. 


\section{ANEXOS}

\section{A.1. Reglas de las Subastas}

En el caso de pesquerías industriales en Estado de Recuperación o de Desarrollo Incipiente ${ }^{19}$, la Ley de Pesca chilena autoriza a Subpesca, la agencia regulatoria sectorial, para adjudicar en subasta pública Cuotas Individuales Transferibles (CITs). Al inicio del proceso de subastas de CITs, la pesquería del Bacalao de Profundidad estaba en Desarrollo Incipiente.

Las CITs equivalen a derechos de pesca transitorios, válidos por 10 años y expresados como derechos porcentuales sobre la cuota global anual (CTP) fijada cada año. La $C T P$ se fija mediante un proceso conjunto entre Subpesca y el Consejo Nacional de Pesca, instancia con representación de distintos grupos de interés (Peña-Torres, 2002).

Un Decreto de Subpesca definió los procedimientos por usarse en las subastas y el tipo de lotes por vender, lo que se resume a continuación. En la primera subasta anual se adjudica el $100 \%$ o $90 \%{ }^{20}$ de la CTP correspondiente, asignando CITs que corresponden a permisos de pesca con coeficiente variable, i.e. a partir del segundo año cada CIT disminuye su valor en $10 \%$ por año, expirando del todo su valor al término de los 10 años de vigencia de estos derechos. Cuando en la subasta inicial se adjudica el $90 \%$ de la CTP, como fue el caso de la pesquería bajo análisis, se licitan 31 lotes en total, de forma secuencial y en un único acto. Tres de estos lotes deben corresponder, cada uno, a derechos de pesca equivalentes al 10\% de la CTP anual. Otros ocho lotes proveerán, cada uno, derechos de pesca por el 5\% de la CTP, mientras que los 10 lotes restantes corresponderán, cada uno, a derechos por el $1 \%$ de la CTP anual. La motivación de Subpesca para definir de esta forma los lotes a subastar era incentivar así la participación de las firmas más pequeñas en las subastas.

A partir del segundo año se continúan efectuando subastas anuales de CITs, siendo éstas nuevamente válidas por diez años y equivalentes a derechos

19 Pesquerías En recuperación son aquellas que se reabren luego de permanecer durante al menos tres años consecutivos cerradas por veda total. Pesquerías en Desarrollo incipiente corresponden a aquellas cuyos niveles iniciales de desembarque (al momento de declararlas en este estatus) no sobrepasan al 10\% de la estimación de CTP o cuota global anual para esa pesquería.

20 En pesquerías de desarrollo incipiente y en donde existan declaraciones de desembarque en fechas previas a la primera subasta, el regulador pesquero puede asignar según presencia histórica hasta el $10 \%$ de la CTP proyectada, y el resto vía subasta pública. En caso que existan desembarques previos declarados, se asignan CITs con vigencia inicial de tres años por el equivalente al $10 \%$ de la $C T P$, entre las empresas que declararon esos desembarques, y luego estas CITs se renuevan por otros diez años, distribuyéndolas según los porcentajes de pesca logrados por esas empresas durante los tres primeros años de operación del sistema de CITs. 
porcentuales sobre la CTP de cada año. No obstante, las CITs vendidas desde la segunda subasta anual en adelante no pierden gradualmente su valor, sino de una vez y por completo al término del décimo año de vigencia. Cuando en la primera subasta se licita el $90 \%$ de la $C T P$, en cada subasta anual siguiente se licitará sólo el $9 \%$ de la CTP, dividido en 9 lotes de $1 \%$ cada uno. Este $9 \%$ anual corresponde al 10\% anualmente liberado del total de CTP licitado en la primera subasta. Así, desde la segunda subasta en adelante se venderán lotes homogéneos en términos de los derechos de pesca que ellos implican. Nótese que los dos intentos de entrada que se analizan en este trabajo ocurren en subastas de este último tipo.

Otros aspectos relevantes del procedimiento de subasta son los siguientes: (1) Las reglas de licitación prohíben que una misma persona, natural o jurídica, pueda adjudicarse más del $50 \%$ del total a subastar, directamente o a través de terceros. ${ }^{21}$ (2) En cada subasta Subpesca fija un precio mínimo de subasta. $^{22}$ (3) La subasta se efectúa en un solo acto, vendiéndose cada lote en forma secuencial, siguiendo el orden dispuesto ex ante en las bases de cada licitación, y con las ofertas de precios expresadas a viva voz. (4) Cada lote se adjudica a la postura más alta que se exprese (subasta tipo inglesa) por sobre el precio mínimo fijado. (5) El valor de cada lote adjudicado se paga en 10 cuotas anuales de valor idéntico. (6) Las CITs subastadas pueden luego ser vendidas o arrendadas. ${ }^{23}$

A partir de la subasta de diciembre de 2003, Subpesca modificó las reglas de licitación de los derechos de pesca para el bacalao de profundidad en Chile. Desde entonces se comenzó a usar subastas orales de precio descendente (subasta Holandesa), en las cuales el precio mínimo pasó a ser desconocido para los participantes en cada licitación. En este trabajo no se analizan los resultados de las subastas bajo estas nuevas reglas de licitación. Fernández (2008) resume los resultados observados en las subastas sujetas al nuevo esquema de licitación.

21 No obstante, no existe límite al porcentaje de la CTP que un mismo participante se puede adjudicar, en forma acumulada, en una serie de subastas sucesivas.

22 En la primera subasta (diciembre de 1992) el cálculo del precio de reserva consideró los costos de investigación y administración asociados a este recurso, como también el valor de productos procesados en esta pesquería. Desde la segunda subasta en adelante, el precio de reserva en cada nueva subasta (año t) ha correspondido al precio de reserva definido para la subasta en el año t-1, multiplicado por la razón entre la CTP del año t y la CTP en $\mathrm{t}-1$. Hasta la subasta de diciembre de 2002, el precio mínimo, fijado de forma ex ante a cada subasta anual, era conocido con al menos dos meses de antelación por los interesados en participar en cada subasta.

23 Los adjudicatarios de CITs quedan inscritos en un registro a cargo de la agencia fiscalizadora del sector pesquero (Sernapesca), en donde también se registran los posteriores cambios de propiedad y arriendos. Sin embargo, el precio de estas transacciones no queda registrado. 


\section{A.2. Prueba Proposición 2}

La Proposición 2 asume que la valoración del entrante por un lote es mayor que la máxima valoración de cada incumbente:

$$
\Pi^{i}(Q)-\Pi^{i}\left(Q+q_{l}\right)<\Pi^{e}\left(Q+q_{l}\right)
$$

Adicionalmente se asume una secuencia infinita de subjuegos idénticos e independientes entre sí. Una estrategia óptima para el potencial entrante es ofertar en cada subjuego una puja que sea mayor que la valoración de los incumbentes y menor o igual que la valoración $\operatorname{propia}^{24}\left(\Pi^{i}(Q)-\Pi^{i}\left(Q+q_{l}\right)<b^{e} \leq \Pi^{e}\left(Q+q_{l}\right)\right)$. Ante esta estrategia, la mejor respuesta (no cooperativa) de los incumbentes será ofrecer un valor necesariamente menor a la oferta del entrante. Así, en cada subjuego, el único equilibrio Nash perfecto de 'mano temblorosa' (Selten 1975) ${ }^{25}$ será que los incumbentes oferten exactamente su valoración, mientras que el entrante ofertará una unidad por sobre aquella. En este caso el entrante consigue adquirir el lote en subasta, siendo por lo tanto el beneficio para cada incumbente, en cada subjuego repetido infinitas veces, igual a $w_{i}^{N E}=\Pi^{i}\left(Q+q_{l}\right)$.

Supóngase ahora que un grupo de $1<n \leq$ I incumbentes (tal que $n \cdot V^{i}>V^{e}$ ) se coluden para pagar de manera conjunta el costo de la disuasión de entrada en la serie infinita de subastas, mediante el siguiente mecanismo: $\operatorname{los} n$ incumbentes pertenecientes al acuerdo ofrecen exactamente la valoración del entrante y por lo tanto empatan en la subasta debiendo pagar cada uno la $n$-ésima parte e impidiendo la adquisición del lote por el entrante. Si es que alguno de los incumbentes coludidos se desvía al menos una vez del acuerdo, éstos vuelven para siempre al equilibrio Nash no colusorio de cada subjuego, en el cual cada uno oferta su valoración y el potencial entrante consigue adquirir en cada subasta el lote subastado. Esta amenaza es creíble ya que, dado el desvío, ningún incumbente tiene incentivos a realizar unilateralmente una estrategia distinta a la propuesta en la fase de castigo. Esto porque la estrategia de castigo es un equilibrio Nash de mano temblorosa en cada subjuego.

Para cada incumbente perteneciente al acuerdo colusorio, el beneficio en cada subjuego de mantenerse en el acuerdo es: $w^{c o l}=\Pi^{i}(Q)-\frac{\Pi^{e}\left(Q+q_{l}\right)}{n}$, mientras que el beneficio de los $(I-n)$ restantes incumbentes (free riders) será $\Pi^{i}(Q)$. El beneficio de un incumbente que se desvíe del acuerdo colusorio, en el período de desvío, sería equivalente al de los free riders (denótese por $w^{d e v}=\Pi^{i}(Q)$ ).

\footnotetext{
24 Como la subasta es de segundo precio, con esta estrategia el entrante se asegura pagar, como máximo, su propia valoración.

25 El equilibrio Nash perfecto de 'Mano Temblorosa' elimina el uso de estrategias débilmente dominadas. De forma consistente, al analizar subastas secuenciales con $L>1$ lotes se utiliza una sofisticación del Equilibrio Markoviano que también excluye el uso de estrategias débilmente dominadas.
} 
Luego de la ocurrencia del desvío, el beneficio para cualquier incumbente en cada futura subasta sería $w^{N E}=\Pi^{i}\left(Q+q_{l}\right)$

Si los n incumbentes juegan una estrategia trigger como la descrita, la colusión será factible en tanto los pagos esperados de estar coludidos (lado derecho de la ecuación 2.2) sean mayores o iguales que los pagos esperados de desviarse (lado izquierdo de la ecuación 2.2), i.e.:

$$
\begin{gathered}
w^{\text {desv }}+\delta \cdot w^{N E}+\delta^{2} \cdot w^{N E}+\ldots \leq w^{c o l}+\delta \cdot w^{c o l}+\delta^{2} \cdot w^{c o l}+\ldots \\
\Rightarrow w^{\text {desv }}+\frac{\delta}{1-\delta} w^{N E} \leq w^{c o l} \cdot \frac{1}{1-\delta} \Rightarrow \delta \geq \frac{w^{\text {desv }}-w^{c o l}}{w^{\text {desv }}-w^{N E}}
\end{gathered}
$$

donde $\delta=(1 / 1+r)<1$, siendo $r$ la tasa de descuento.

$$
\Rightarrow \delta \geq \frac{V^{e}}{n \cdot V^{i}}
$$

\section{A.3. Prueba Proposición 3}

Esta demostración consta de cuatro partes (A a D). En la primera se define la valoración de cada incumbente y la valoración del potencial entrante por un lote. En la segunda se demuestra que $V^{e}>V^{i} \Rightarrow I>1$. En la tercera parte se demuestra que:

$$
I>1, V^{e}>V^{i} \Rightarrow \frac{F}{(a-c)^{2}}<\frac{I^{2}-2}{[(1+I) \cdot(2+I)]^{2}}
$$

Y en la última parte se demuestra que, cuando se cumplen las condiciones (i) y (ii) de la Proposición 3, existirá una cantidad $q_{l}^{*}$, a partir de la cual $V^{e}>V^{i}$, tal que:

$$
q_{l}^{*}=\frac{(a-c)(I-1)-\sqrt{(a-c)^{2}(I-1)^{2}-4 \cdot I \cdot F(I+1)}}{2 I}
$$

(A) Definición de $V^{e}$ y $V^{i}$.

La valoración de un incumbente representativo, si es que el potencial entrante va a adquirir el único lote subastado, será la pérdida de beneficio en la etapa Cournot que ocasione la compra del entrante, i.e.: 


$$
V^{i}=\Pi^{i}(Q)-\Pi^{i}\left(Q+q_{l}\right)
$$

Resolviendo el juego Cournot con I firmas no restringidas idénticas y ningún entrante en la etapa final, el beneficio de cada firma incumbente será:

$$
\Pi^{i}(Q)=\left(\frac{a-c}{I+1}\right)^{2}
$$

El beneficio de cada firma incumbente en la etapa final, cuando el entrante adquiere el único lote subastado y entra como un agente restringido, será:

$$
\Pi^{i}\left(Q+q_{l}\right)=\left(\frac{a-c-q_{l}}{I+1}\right)^{2}
$$

Reemplazando las formas funcionales en la valoración del incumbente representativo, se obtiene:

$$
V^{i}=\frac{2(a-c) \cdot q_{l}-q_{l}^{2}}{(1+I)^{2}}
$$

La valoración del entrante (que son los beneficios que obtiene en la última etapa por comercializar las toneladas adquiridas en la subasta), será igual a:

$$
V^{e}=\frac{(a-c) \cdot q_{l}-q_{l}^{2}}{(1+I)}-F
$$

(B) $V^{e}>V^{i} \Rightarrow I>1$

Se busca, para $I=1$, si existe algún valor $q_{l}$ tal que $V^{e}>V^{i}$. Reemplazando (3.1) y (3.2) se obtiene que $V^{e}>V^{i}$ si:

$$
\frac{(a-c) \cdot q_{l}-q_{l}^{2}}{2}-F>\frac{2 \cdot(a-c) \cdot q_{l}-q_{l}^{2}}{4}
$$

Reordenando esta desigualdad, se obtiene que $q_{l}^{2}<-4 \cdot F$, lo cual es una contradicción, por lo tanto: $V^{e}>V^{i} \Rightarrow(i) \quad I>1$.

(C) Si $I>1$ y $V^{e}>V^{i} \Rightarrow \frac{F}{(a-c)^{2}}<\frac{I^{2}-2}{[(1+I) \cdot(2+I)]^{2}}$ 
Reemplazando (3.1) y (3.2) se obtiene $V^{e}>V^{i}$ si:

$$
F<q_{l} \frac{\left[(a-c)(I-1)-I \cdot q_{l}\right]}{(1+I)^{2}}
$$

Como se cumple que $\left(\frac{\left(I^{2}-2\right) \cdot(a-c)^{2}}{[(1+I) \cdot(2+I)]^{2}}\right) \geq\left(q_{l} \frac{\left[(a-c)(I-1)-I \cdot q_{l}\right]}{(1+I)^{2}}\right)$ para cualquier $q_{l} \leq \frac{a-c}{2+I}$ (i.e., rango de valores de $q_{l}$ en los cuales la firma entrante siempre es un agente restringido en la etapa Cournot), entonces:

$$
\text { Si } I>1 \text { y } V^{e}>V^{i} \Rightarrow \quad \text { (ii) } \frac{F}{(a-c)^{2}}<\frac{I^{2}-2}{[(1+I) \cdot(2+I)]^{2}}
$$

(D) Cumpliéndose las condiciones (i) y (ii) en la Proposición $3=>$ si $q_{l}>q_{l}^{*}$, donde

$$
q_{l}^{*}=\frac{(a-c)(I-1)-\sqrt{(a-c)^{2}(I-1)^{2}-4 \cdot I \cdot F(I+1)}}{2 I} \Rightarrow V^{e}>V^{i}
$$

El valor de esta cantidad crítica $q_{l}^{*}$, a partir de la cual la valoración del potencial entrante es mayor que la pérdida que ocasiona a cada incumbente, se deduce igualando $V^{e}=V^{i}$. Se busca un valor $q_{l}{ }^{*}$ tal que el potencial entrante, en caso de entrar a la industria, lo haga como un agente restringido, i.e. $q_{l} \leq \frac{a-c}{2+I}$. Reemplazando las valoraciones del incumbente representativo y del potencial entrante:

$$
\begin{aligned}
& \frac{2(a-c) \cdot q_{l}-q_{l}^{2}}{(1+I)^{2}}=\frac{(a-c) \cdot q_{l}-q_{l}^{2}}{(1+I)}-F \\
& \Rightarrow q_{l}^{*}=\frac{(a-c)(I-1)-\sqrt{(a-c)^{2}(I-1)^{2}-4 \cdot I \cdot F(I+1)}}{2 I}
\end{aligned}
$$

Note que $q_{l}^{*}=0$ cuando $\mathrm{F}=0$, y que además $q_{l} *$ aumenta conforme se incrementa $\mathrm{F}>0$. Por lo tanto, para que el entrante pueda adquirir un lote en las subastas, deberán cumplirse copulativamente las tres condiciones señaladas (i, ii, y iii) en la Proposición 3. 


\section{A.4. Prueba Proposición 4}

La Proposición 4 supone que (ii) $V^{i} \geq V^{e}$ con $\mathrm{L}=1$, lo que implica respecto al costo fijo la siguiente condición:

$$
V^{i} \geq V^{e} \Rightarrow \frac{2(a-c) \cdot q_{l}-q_{l}^{2}}{(1+I)^{2}} \geq \frac{\left(a-c-q_{l}\right) \cdot q_{l}}{1+I}-F \quad \Rightarrow F \geq q_{l} \frac{\left[(a-c)(I-1)-I \cdot q_{l}\right]}{(1+I)^{2}}
$$

Asimismo, y con L $>1$ lotes, un incumbente no puede disuadir más de 2 veces, i.e:

$$
\begin{aligned}
& 2 \cdot V_{l}^{e}\left(h_{l}=0\right)>V_{l}^{i}\left(h_{l}=0\right) \quad \Rightarrow 2 \cdot\left(\frac{a-c-q_{l}}{I+1}\right) \cdot q_{l}-2 \cdot F>\left(\frac{2 \cdot(a-c)-q_{l}}{(I+1)^{2}}\right) \cdot\left(q_{l}\right) \\
& \Rightarrow F<\frac{q_{l}}{(I+1)^{2}} \cdot\left(I \cdot\left(a-c-q_{l}\right)-q_{l} / 2\right)
\end{aligned}
$$

Así, las condiciones (ii) y (iii) significan que la Proposición 4 es válida para un rango de valores de $F$. Este rango de valores no es vacío, ya que $\left((a-c) \cdot(I-1)-I \cdot q_{l}\right)<\left(I \cdot\left(a-c-q_{l}\right)-q_{l} / 2\right)$, para todo $q_{l}<2 \cdot(a-c)$, lo que se cumple, ya que uno de los supuestos base del modelo es que la cantidad total subastada $\left(L \cdot q_{1}\right)$ es menor que la cantidad óptima de Cournot para el incumbente representativo, en el caso que ocurra entrada (supuesto que asegura que el potencial entrante siempre es un agente restringido), i.e.:

$$
q_{l}<\left(\frac{a-c}{I+2}\right) \cdot \frac{1}{L}
$$

Para efectos de esta demostración, ordénese a los $\mathrm{I} \geq 2$ incumbentes según el número (secuencial) del lote que cada uno pretende adquirir: $\mathrm{i}=1$ piensa adquirir el lote 1 y así hasta el lote número L que pretende adquirir i $=\mathrm{L} . \mathrm{Si}$ existen más incumbentes que número de lotes, existirán incumbentes que se beneficiarán vía free riding de los costos que asumen los restantes incumbentes para disuadir la entrada de un nuevo rival.

Sea I $\geq \mathrm{L}$ : Resolviendo por inducción hacia atrás, se inicia analizando el conjunto de historias posibles al licitar el último lote $\mathrm{L}$, i.e. $H_{L}=(0,1,2, \ldots, L-1)$. Así, si $h_{L}=L-1$, es decir si el entrante hubiese adquirido los L-1 lotes anteriores, la valoración del entrante por el lote L será:

$$
\begin{gathered}
V_{L}^{e}\left(h_{L}=L-1\right)=\Pi^{e}\left(Q+L \cdot q_{l}\right)-\Pi^{e}\left(Q+(L-1) \cdot q_{l}\right) \Rightarrow \\
\Rightarrow V_{L}^{e}\left(h_{L}=L-1\right)=\frac{(a-c) \cdot q_{l}-q_{l}^{2} \cdot(2 \cdot L-1)}{1+I}
\end{gathered}
$$


Mientras que la valoración del incumbente i $=$ L por el lote L será:

$$
V_{L}^{i=L}\left(h_{L}=L-1\right)=\frac{q_{l}}{(1+I)^{2}} \cdot\left(2(a-c)-(2 L-1) q_{l}\right)
$$

Para que el entrante no adquiera el lote L debe cumplirse que:

$$
\frac{q_{l}}{(1+I)^{2}} \cdot\left(2(a-c)-(2 \cdot L-1) \cdot q_{l}\right) \geq \frac{(a-c) \cdot q_{l}-q_{l}^{2} \cdot(2 \cdot L-1)}{1+I}
$$

$$
\Rightarrow q_{l} \leq\left(\frac{I-1}{I}\right) \cdot\left(\frac{a-c}{2 \cdot L-1}\right)
$$

Por otro lado, dada la condición (4.1) y que además se puede demostrar que: $\left(\frac{a-c}{I+2}\right) \cdot \frac{1}{L}<\left(\frac{I-1}{I}\right) \cdot\left(\frac{a-c}{2 \cdot L-1}\right)$ se cumple $\forall I \geq 2$, entonces necesariamente se cumplirá que $\mathrm{i}=\mathrm{L}$ compra el L-ésimo lote en caso que el entrante ya hubiese adquirido los demás, pagando por este lote $V_{L}^{e}\left(h_{L}=L-1\right)$.

Si la historia vigente cuando se licita el lote $L$ fuese $h_{L}=L-2$, la condición para que la valoración del incumbente L sea mayor o igual que la valoración del entrante (por ese lote L) será:

$$
q_{l} \leq\left(\frac{I-1}{I}\right)\left(\frac{a-c}{2 L-3}\right)
$$

Dado que la condición (4.5) es menos exigente que la condición (4.4), i.e.:

$$
\left(\frac{I-1}{I}\right) \cdot\left(\frac{a-c}{2 \cdot L-1}\right)<\left(\frac{I-1}{I}\right) \cdot\left(\frac{a-c}{2 \cdot L-3}\right)
$$

Entonces, mientras menos lotes tuviese acumulados el entrante al momento de la subasta L, más factible será que la firma incumbente adquiera el último lote licitado. En efecto, la condición necesaria para que el incumbente L se adjudique el L-ésimo lote en venta será cada vez menos restrictiva en tanto el entrante tenga menos lotes acumulados. Esto implica que siempre el L-ésimo incumbente adquirirá el lote L. Para el incumbente L-1 y todos los precedentes se aplica el mismo razonamiento. Así, por inducción hacia atrás se obtiene que la única historia posible es $h_{L+1}=0$. Por lo tanto, en todas las etapas de subasta 
un incumbente diferente disuade la entrada del potencial nuevo rival, pagando en cada caso $V_{1}^{e}=\Pi^{e}\left(Q+q_{l}\right)$. Adicionalmente, dada la condición (iii) cada incumbente no podrá disuadir más de una vez la entrada del nuevo rival. Así, el único equilibrio posible será uno en donde cada incumbente necesario para evitar totalmente la entrada del nuevo rival, pagará sólo una vez el costo de adquirir un lote en cada subjuego de subasta con L lotes.

\section{A.5. Prueba Corolario 4.1}

La condición (ii) implica que:

$$
\underline{n} V^{i}=V^{e} \Rightarrow F=Q_{l} \frac{\left[(a-c)(I+1-2 \cdot \underline{n})-Q_{l} \cdot(I+1-\underline{n})\right]}{(1+I)^{2}} \geq 0
$$

Al igual que en la demostración de la Proposición 4, se ordenan a los I > 1 incumbentes según el número (secuencial) del lote que cada uno pretende adquirir. Resolviendo por inducción hacia atrás, se inicia analizando el caso en que el incumbente $\mathrm{i}=\mathrm{L}$ observa, al momento de la subasta del L-ésimo lote, $h_{L}=0$. En este caso, la valoración del entrante por el lote L será:

$$
V_{L}^{e}\left(h_{L}=0\right)=\frac{(a-c) \cdot q_{l}-q_{l}^{2}}{1+I}-F
$$

Mientras que la valoración del incumbente i $=$ L por el lote L será:

$$
V_{L}^{i=L}\left(h_{L}=0\right)=\frac{q_{l}}{(1+I)^{2}} \cdot\left(2(a-c)-q_{l}\right)
$$

Para que el entrante no adquiera el lote L, deberá cumplirse que (5.2) sea mayor o igual que (5.1):

$$
\Rightarrow F \geq q_{l} \frac{\left[(a-c)(I-1)-I \cdot q_{l}\right]}{(1+I)^{2}}
$$

Dado el supuesto $\mathrm{L}=\mathrm{I}>1$, entonces $\mathrm{q}_{1}=\mathrm{Q}_{\mathrm{l}} / \mathrm{I}$. En este caso, la condición (5.3) será:

$$
F \geq \frac{Q_{l}}{I} \cdot \frac{\left[(a-c)(I-1)-Q_{l}\right]}{(1+I)^{2}}
$$


Luego, combinando (5.4) con la condición (ii) del Corolario, obtenemos:

$$
\begin{gathered}
Q_{l} \frac{\left[(a-c)(I+1-2 \cdot \underline{n})-Q_{l} \cdot(I+1-\underline{n})\right]}{(1+I)^{2}} \geq \frac{Q_{l}}{I} \frac{\left[(a-c)(I-1)-Q_{l}\right]}{(1+I)^{2}} \\
\Rightarrow Q_{l} \leq(a-c) \cdot\left(\frac{I \cdot(I-2 \cdot \underline{n})+1}{I \cdot(I+1-\underline{n})-1}\right)>0
\end{gathered}
$$

Por lo tanto, la condición (iii) del Corolario es suficiente para que el incumbente $\mathrm{i}=\mathrm{L}$ adquiera el lote en subasta. El incumbente $\mathrm{i}=\mathrm{L}-1$, si observa la historia $\mathrm{h}_{\mathrm{L}-1}=0$, sabe que al adquirir el lote el incumbente $\mathrm{i}=\mathrm{L}$, adquirirá el lote faltante. Por lo tanto, dado $\mathrm{h}_{\mathrm{L}-1}=0$ la condición (iii) también es suficiente para que el incumbente $\mathrm{i}=\mathrm{L}-1$ adquiera el lote en subasta. El mismo razonamiento se aplica a todos los incumbentes, por lo cual existe al menos un EMRND en donde cada incumbente adquiere un lote y el entrante no logra entrar.

\section{A.6. Prueba Lema 4.2}

Cuando se licitan L > 1 lotes, El CTDE equivaldrá a L veces la valoración del entrante por el primer lote posible de ser adquirido:

$$
L \cdot \Pi^{e}\left(q_{l}\right)=L \cdot\left(\frac{a-c-\left(Q_{l} / L\right)}{I+1}\right) \cdot \frac{Q_{l}}{L}-L \cdot F
$$

Esta demostración se divide en dos partes (A y B). En la Parte (A) se demuestra que el CTDE será mayor (menor o igual) cuando $\mathrm{L}>1$, en relación al caso cuando $\mathrm{L}=1$, siempre que se cumpla la condición (i) del Lema. En la Parte (B) se calcula la pendiente del CTD con respecto a L y se evalúa en qué tramos de la función ésta es creciente, decreciente o constante (condición ii)

$$
L \cdot \Pi^{e}\left(q_{l}\right)>(\leq) \Pi^{e}\left(Q_{l}\right) \Rightarrow(i) L<(\geq) \frac{Q_{l}^{2}}{F \cdot(I+1)}
$$

En efecto:

$$
\left(\frac{a-c-Q_{l} / L}{I+1}\right) \cdot Q_{l}-L \cdot F>(\leq)\left(\frac{a-c-Q_{l}}{I+1}\right) \cdot Q_{l}-F \Rightarrow L<(\geq) \frac{Q_{l}^{2}}{(I+1) \cdot F}
$$


(B) $\frac{\partial\left(L \cdot \Pi^{e}\left(q_{l}\right)\right)}{\partial L}>(\leq) 0$, dependiendo de la siguiente condición: (ii) $L<(\geq) \frac{Q_{l}}{\sqrt{F \cdot(I+1)}}$

La derivada parcial con respecto a L de la expresión en (6.1) será:

$$
\frac{\partial L \cdot \Pi^{e}\left(q_{l}\right)}{\partial L}=\frac{L}{I+1} \cdot\left(2 \cdot \frac{Q_{l}^{2}}{L^{3}}-\frac{Q_{l}}{L^{2}} \cdot(a-c)\right)+\left(\frac{a-c-Q_{l} / L}{I+1}\right) \cdot \frac{Q_{l}}{L}-F
$$

La expresión (6.2) será positiva (negativa o cero) siempre que se cumpla la siguiente condición:

$$
\text { (ii) } L<(\geq) \frac{Q_{l}}{\sqrt{F \cdot(I+1)}}
$$

\section{A.7. Prueba Proposición 5}

La Condición (iii) de la Proposición 5 asegura que en cada subjuego el EMRND define estrategias que permiten al entrante adquirir todos los lotes subastados. Esto porque esa condición es exactamente la opuesta a la Condición (iii) del Corolario 4.1, que aseguraba que el incumbente $\mathrm{i}=\mathrm{L}$, dado $h_{L}=0$, adquiriera el último lote subastado. Lo anterior implica que la condición (iii) de la Proposición 5 asegura que el último incumbente no se interese en adquirir el L-ésimo lote subastado, ni siquiera si es el único que podría obtener el entrante.

En la Proposición 4 se demostró que mientras menos lotes tiene acumulados el entrante, un incumbente cualquiera tendrá mayores incentivos para disuadir su entrada. Así, si el incumbente $\mathrm{i}=\mathrm{L}$ no puede disuadir la entrada cuando $h_{L}=0$, no disuadirá la entrada para ninguna historia posible $h_{L}>0$. El equilibrio no colusorio descrito da a los incumbentes en cada subjuego el siguiente beneficio:

$$
w^{N E}=\Pi^{i}\left(Q+L \cdot q_{l}\right)
$$

Por otro lado, el beneficio de un acuerdo colusorio como el de la Proposición 5, en cada subjuego, es el beneficio obtenido en la fase Cournot en caso que se haya disuadido totalmente la entrada, menos el CTDE dividido entre el número de incumbentes coludidos: 


$$
w^{c o l}=\Pi^{i}(Q)-\frac{L \cdot \Pi^{e}\left(Q+q_{l}\right)}{n}
$$

Para que a los incumbentes les interese realizar un acuerdo colusorio debe cumplirse que $w^{c o l}>w^{N E}$, lo que implica que $n>\left(L \cdot \Pi^{e}\left(Q+q_{l}\right) / V^{i}\right)$. Finalmente, el desvío óptimo para un incumbente que pertenece al acuerdo colusorio es no pagar su parte del CTDE y aprovechar durante el período de desvío el beneficio de ser free rider $\left(w^{\text {desv }}=\Pi^{i}(Q)\right)$. El castigo que aplican los miembros del acuerdo en caso de desvío es volver para siempre al equilibrio no colusorio ya descrito (que permite entrada completa). Para que la colusión sea posible, deberá cumplirse:

$$
w^{d e s v}+\frac{\delta}{1-\delta} w^{N E} \leq w^{c o l} \cdot \frac{1}{1-\delta} \Rightarrow \delta \geq \frac{w^{d e s v}-w^{c o l}}{w^{d e s v}-w^{N E}}
$$

Reemplazando en (7.3):

$$
\delta \geq \frac{L \cdot \Pi^{e}\left(Q+q_{l}\right)}{n \cdot\left(\Pi^{i}(Q)-\Pi^{i}\left(Q+L \cdot q_{l}\right)\right)}=\frac{L \cdot \Pi^{e}\left(Q+q_{l}\right)}{n \cdot V^{i}}
$$

Luego, el factor mínimo de descuento que viabiliza la colusión será: $\underline{\delta}=\frac{L \cdot \Pi^{e}\left(Q+q_{l}\right)}{n \cdot V^{i}}$. 